OPEN ACCESS

Edited by:

Ester Pagano,

University of Naples Federico II, Italy

Reviewed by:

Oksana Zayachkivska,

Danylo Halytsky Lviv National Medical University, Ukraine

Izumi Kaji,

Vanderbilt University Medical Center, United States

*Correspondence:

Giorgia Colombo giorgia.colombo@uniupo.it

Specialty section: This article was submitted to Gastrointestinal and Hepatic Pharmacology,

a section of the journal

Frontiers in Pharmacology

Received: 13 August 2021 Accepted: 02 November 2021 Published: 22 November 2021

Citation:

Colombo G, Gelardi ELM,

Balestrero FC, Moro M, Travelli $C$ and Genazzani AA (2021) Insight Into Nicotinamide Adenine Dinucleotide Homeostasis as a Targetable

Metabolic Pathway in

Colorectal Cancer.

Front. Pharmacol. 12:758320. doi: 10.3389/fphar.2021.758320

\section{Insight Into Nicotinamide Adenine Dinucleotide Homeostasis as a Targetable Metabolic Pathway in Colorectal Cancer}

\author{
Giorgia Colombo ${ }^{1 *}$, Edoardo Luigi Maria Gelardi ${ }^{2}$, Federica Carolina Balestrero ${ }^{1}$, \\ Marianna Moro ${ }^{1}$, Cristina Travelli ${ }^{3}$ and Armando A. Genazzani ${ }^{1}$
}

${ }^{1}$ Department of Pharmaceutical Sciences, Università Del Piemonte Orientale, Novara, Italy, ${ }^{2}$ Department of Experimental Oncology, European Institute of Oncology IRCCS, Milan, Italy, ${ }^{3}$ Department of Drug Sciences, Università Degli Studi di Pavia, Pavia, Italy

Tumour cells modify their cellular metabolism with the aim to sustain uncontrolled proliferation. Cancer cells necessitate adequate amounts of NAD and NADPH to support several enzymes that are usually overexpressed and/or overactivated. Nicotinamide adenine dinucleotide (NAD) is an essential cofactor and substrate of several NAD-consuming enzymes, such as PARPs and sirtuins, while NADPH is important in the regulation of the redox status in cells. The present review explores the rationale for targeting the key enzymes that maintain the cellular NAD/NADPH pool in colorectal cancer and the enzymes that consume or use NADP $(H)$.

Keywords: NAD, NADPH, NAMPT (nicotinamide phosphoribosyltransferase), isocitrate dehydrogenase (IDH), CD38, ALDH = aldehyde dehydrogenase, PARP, sirtuins

\section{INTRODUCTION}

Colorectal cancer (CRC), a frequent cancer that occurs in both males and females (Kim HI. et al., 2018), is characterized by an high rate of mortality (Brody, 2015). Overall, 5 -years survival rates are high, around $90 \%$, but this percentage decreases to $66 \%$ in patients with regional lesions and metastasis (Koyanagi et al., 2008). From a therapeutic point of view, new drugs have extended the survival rate, but there is still a strong unmet medical need in advanced or metastatic CRC, in particular due to chemotherapy/target therapy resistance and unresponsiveness to new therapies (Brody, 2015; Loree and Kopetz, 2017). Finding new therapeutic strategies in CRC is therefore both challenging and necessary.

Among the cancer features that define aggressiveness, there is the reprogramming of cellular metabolism (Loree and Kopetz, 2017). Abnormal consumption of glucose and increased production of lactate, with a subsequent decrease of oxidative phosphorylation through aerobic glycolysis, is defined as the "Warburg effect", and allows cancer cells to win the evolutionary game of the "survival of the fittest" thereby allowing them to proliferate both in aerobic and anaerobic environments (Vander Heiden et al., 2009). Therefore, also gluconeogenesis, that is opposed to aerobic glycolysis, is able to hijack cell plasticity, promoting tumour growth (Grasmann et al., 2019). Nicotinamide adenine dinucleotide (NAD) and nicotinamide adenine dinucleotide phosphate (NADPH) are indispensable in regulating these metabolic reactions as well as for adenosine triphosphate (ATP) production. While the ubiquitous nature of these pathways renders their pharmacological targeting challenging, a number of groups have now focused their attention on this possibility. These strategies can be sub-divided in distinct chapters: 1 ) reducing the $\mathrm{NAD}(\mathrm{H})$ supply of cells by inhibiting the 


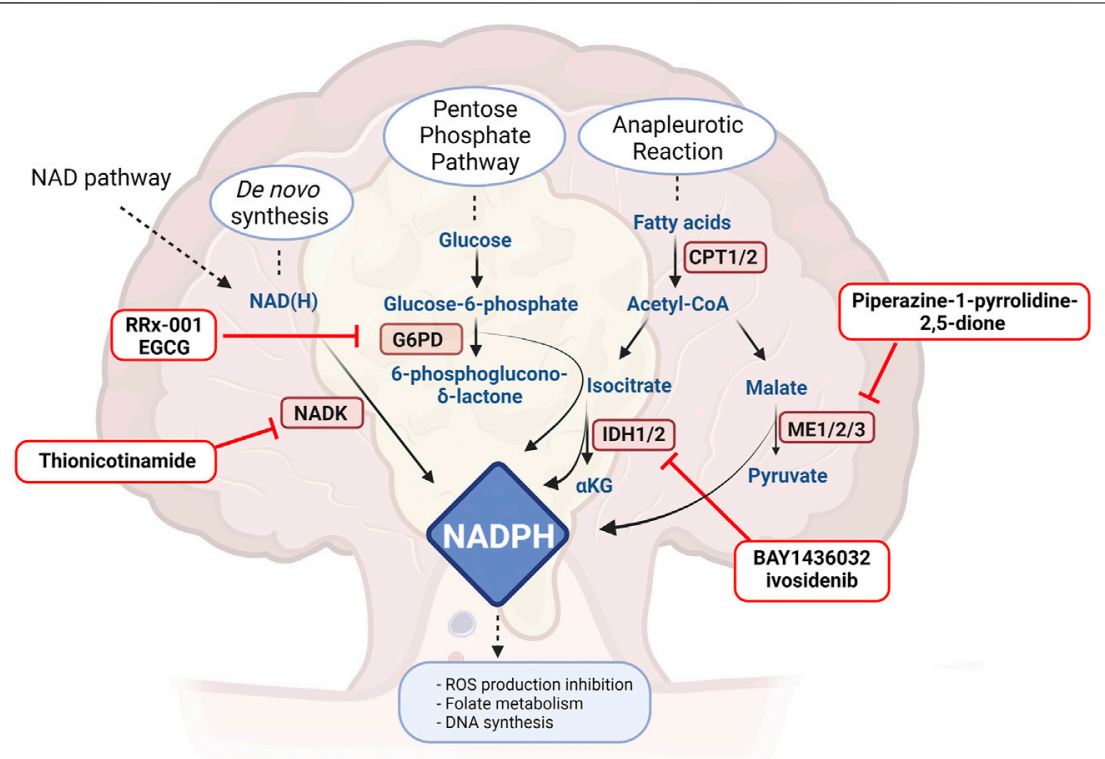

FIGURE 1 | Drugs or molecules that have been postulated as effective in CRC and that target NAD routes. NAMPT: nicotinamide phosphoribosyltransferase, NAPRT: nicotinic acid phosphoribosyltransferase, NMNAT: nicotinamide mononucleotide adenylyltrasnferase, NADSYN: NAD synthetase, PARP: Poly-ADP ribose polymerase, ALDHs: aldehyde dehydrogenase. Created with BioRender.com.

enzymes involved in its synthesis, thereby reducing the activity of all down-stream pathways dependent on this molecule; 2) selectively inhibiting NAD-consuming enzymes: 3) selectively inhibiting enzymes that use $\mathrm{NAD}(\mathrm{P})(\mathrm{H})$ as a co-factor.

Several reviews have addressed the advantage of targeting $\mathrm{NAD} / \mathrm{NADPH}$ homeostasis and consuming enzymes in cancer (Audrito et al., 2019; Galli et al., 2020; Ju et al., 2020; Rather et al., 2021); thus, an extensive description is beyond the purpose of this manuscript, and we refer to other excellent reviews on the subject, including the ones that describe the entire NADome (Chiarugi et al., 2012). In the present review, we have searched on MEDLINE/PubMed the names more than of $400 \mathrm{NAD}$ and NADPH-dependent enzymes followed by the term "colorectal cancer" and have chosen the most relevant, and less reviewed, targets in the context of CRC. In particular, we have included papers pointing out targets in a pharmacological perspective, avoiding results of proteins found exclusively in sequencing analysis.

NAD homeostasis results from the balance between NADconsuming reactions and NAD-biosynthetic routes. Indeed, NAD-consuming enzymes (e.g., poly-ADP-ribose polymerases (PARPs)) are upregulated and have a higher activity in cancer, and metabolic enzymes that require $\mathrm{NAD}(\mathrm{P})$ as a co-factor are also up-regulated, resulting in a higher demand of these molecules which is provided by NAD-synthetic paths. It is therefore not surprising that several manuscripts have investigated the effect of inhibition of these pathways in CRC, as summarized in Figure 1.

\section{NICOTINAMIDE ADENINE DINUCLEOTIDE SYNTHESIS AS A TARGET}

There are four main NAD biosynthetic pathways in eukariotic cells: 1) the de novo biosynthetic Pathway from quinolinic acid, derived from dietary tryptophan, 2) the Preiss-Handler Pathway (PH-pathway) from nicotinic acid (NA), 3) the Salvage Pathway from nicotinamide (NAM), mediated by nicotinamide phosphoribosyltransferase (NAMPT) and 4) the newly described route from nicotinamide riboside (Tempel et al., 2007) through nicotinamide riboside kinase (NMRK). These four pathways converge in the production of a mononucleotide, catalysed by different phosphoribosyltransferase enzymes depending on the starting precursor. In the last step, which is common to all routes, the formation of NAD is catalysed by nicotinamide mononucleotide adenylyltransferase (NMNAT). Nicotinamide is considered the main precursor of NAD due to its availability compared to nicotinic acid: it is present in higher concentrations in the bloodstream, it is easily introduced by diet, and it is the reaction product of NAD-dependent enzymes.

Due to the Warburg effect and to over-activation of NADconsuming enzymes, proliferating cells necessitate larger NAD supplies (La Vecchia and Sebastián, 2020). Chowdhry et al. have highlighted that tumours are usually dependent on the $\mathrm{PH}$ pathway (PH-dependent tumours) or from salvage pathway (salvage-dependent tumours). In general, this is usually linked to whether the original healthy tissue expressed higher levels of either nicotinic acid phosphoribosyltransferase (NAPRT) or NAMPT (Chowdhry et al., 2019). While these two enzymes 
have received considerable attention in cancer, every enzyme that sustains NAD production might be a possible target for targeting CRC.

\section{NAMPT and NAPRT as Drug Targets in Colorectal Cancer}

Nicotinamide phosphoribosyltransferase is the key enzyme of the NAD Salvage Pathway and belongs to type II phosphoribosyltransferases. It exists as a dimer in two different forms: an intracellular form (iNAMPT) that is localized in the cytosol and in the nucleus, and an extracellular form (eNAMPT) that is secreted in extracellular fluids by various cell types. NAPRT is structurally similar and has also been reported to be both intracellular and extracellular.

iNAMPT is situated inside the cell as a homodimer with a molecular weight of about $110 \mathrm{kDa}$. It is involved in NAD biosynthesis and catalyses the production of nicotinamide mononucleotide (NMN) from NAM and 5-phosphoribosyl-1pyrophosphate (PRPP). Since it controls the intracellular levels of NAD (i.e., its inhibition leads to a significant drop in levels), iNAMPT modulates the activity of NAD-dependent enzymes, such as PARPs and sirtuins (SIRTs). NAPRT, instead, uses NA as a substrate.

These two enzymes therefore run parallel routes of synthesis. According to Chowdhry et al., colon cancer cells appear to be NAMPT-dependent, due to lower levels of NAPRT in the primary tissue (Chowdhry et al., 2019), even though other manuscripts reveal a dependence also from NAPRT (Hong et al., 2019) and a higher expression of this latter enzyme in healthy small intestine, colon cancer cell lines and biopsies (Hara et al., 2007; Duarte-Pereira et al., 2016; Cole et al., 2017).

While a number of drug discovery programs have initiated to develop NAPRT inhibitors, potent and selective ligands have so far been elusive, and it is therefore not known whether NAPRT inhibition may be a viable strategy to target CRC. On the contrary, the field of iNAMPT has capitalized on the report, back in 2003, of the first specific nanomolar inhibitor, FK866 or APO866, which has been followed by a number of other inhibitors which have either reached clinical stages (CHS828, GMX1777, KPT9274 and OT82) or have only been carried forward only at the preclinical level (Holen et al., 2008; Pishvaian et al., 2008; Goldinger et al., 2016; Galli et al., 2020).

Alongside the metabolic rationale, it is also known that iNAMPT overexpression is correlated to colorectal carcinoma rather than adenoma and it is therefore not surprising that its inhibition, using FK866, leads to cell death of a number of CRC cell lines, including HT29, HCT116 and Caco-2 (Lv et al., 2015). Similarly, the small molecule GMX1778, another inhibitor that has reached clinical trials, is able to induce antitumour responses in HCT-116 xenograft model (Watson et al., 2009). Similarly, another NAM-competitive inhibitor, named A-1293201, is also effective in the same model (Wilsbacher et al., 2017).

Tolstikov et al. have characterized iNAMPT inhibition in CRC, again using FK866 and mass-spectrometry-based metabolomics (Tolstikov et al., 2014). Using the human HCT116 cell line (Duke's staging type D) and have reported how FK866 is able to hinder several metabolic pathways and their related signalling pathways. In brief, FK866 is able to 1) attenuate glycolysis and the pentose phosphate pathway and thereby lead the accumulation of glycolytic substrates; 2 ) attenuate nucleotide and amino acid metabolism with a subsequent reduction of purine and pyrimidine metabolism; 3) induce reduction of pyruvate entry in the TCA cycle with a consequent reduction in aspartate and alanine synthesis; 4) induce an attenuation of purine biosynthesis, with an accumulation of xanthine; and 5) reduce fatty acid and lipid metabolism (Tolstikov et al., 2014). Alongside metabolism, iNAMPT has also been shown to sustain neoplastic progression acting on cancer stem cells and Wnt/ $\beta$-catenin signalling (Lucena-Cacace et al., 2018; Ye et al., 2020). Indeed, iNAMPT is now considered an oncogene, overexpressed in colon cancer and correlated to poor prognosis, able to promote tumour initiation through cancer initiating cells (CICs), in CICs xenograft using HCT116 and LS180 cell lines (Lucena-Cacace et al., 2018). This overexpression determines chemoresistance mediated by an increase in CD133 + cancer stem cells, overexpressing PARPs and SIRT1, and the treatment with FK866 in combination with olaparib (PARP inhibitor) or sirtinol (SIRT inhibitor) is able to counteract tumour progression (Lucena-Cacace et al., 2018). Moreover, iNAMPT regulates $W n t / \beta$-catenin pathway promoting CRC growth, so using FK866, $\beta$-catenin nuclear translocation and $\mathrm{Wnt} / \beta$-catenin target gene cyclin D1 are hampered. Axin, a component of the $\beta$-catenin demolition complex, is subsequently elevated after FK866 treatment (Ye et al., 2020). On the other hand, the resistance of FK866 may sensitise cells to 5-fluorouracil, cisplatin and $\gamma$-rays in HCT116-resistant cells (Ogino et al., 2018, 2019). Both iNAMPT and NAPRT have been found overexpressed in a model of cancer-associated colitis (CAC), as azoxymethane (AOM)/dextran sodium sulphate (DSS), highlighting a possible effect on inflammation that undergoes cancer development.

In 1994, a cytokine, referable to the extracellular form of NAMPT (eNAMPT), was identified as an immunomodulatory agent able to promote pre- $\mathrm{B}$ cell colony formation synergizing with IL-7 and stem cell factor (SCF) (Samal et al., 1994). Indeed, it has now been ascertained that eNAMPT can also be secreted by a number of different cell types (including cancer cells) and acts as a cytokine that modulates the immune response (Audrito et al., 2015; Camp et al., 2015). It is still unclear whether enzymatic activity is maintained and if it is necessary for its cytokine-like action (Grolla et al., 2016). iNAMPT and eNAMPT have the same amino-acid sequence and the same quaternary structure, but specific post-translational modifications might be responsible for eNAMPT secretion. In particular, it has been suggested that the deacetylation of lysine 53 on iNAMPT, operated by SIRT1, predisposes the protein to secretion and enhances eNAMPT activity in adipocytes (Yoon et al., 2015). No testimony certifies a possible effect of targeting eNAMPT in CRC, even though it has been found elevated in CRC patients (Nakajima et al., 2010), and shown to promote multi-drug resistance (Yan et al., 2017) and increase reactive oxygen species (ROS) (Buldak et al., 2015). Our group and Garcia's have recently developed neutralizing monoclonal antibodies against eNAMPT (Colombo 
et al., 2020; Garcia et al., 2021), and it is possible that in the future data in CRC will be gathered also in this respect although the relationship between eNAMPT and NAD homeostasis is unclear. More recently, also NAPRT has been found in the extracellular space (eNAPRT), elevated in septic patients. Managò et al. have highlighted also its presence in some tumour patients, compared to healthy subjects, but more information needs to be gathered (Managò et al., 2019).

Overall, therefore, iNAMPT inhibition would appear as a plausible target. While efficacy would be supported by the above data, there are nonetheless doubts regarding safety, with a number of on-target side effects (Olesen et al., 2010; Tarrant et al., 2015), probably due to the ubiquitous nature of this enzyme. The verdict is not final, though, as there are dual agents (PAK4 p21-activated kinase and NAMPT dual inhibitor) in the clinic and a series of NAMPT inhibitors has been reported as not having these side effects in preclinical tests (Abu Aboud et al., 2016; Travelli et al., 2019a; Galli et al., 2020). Moreover, iNAMPT has appeared to be a promising target also in the immune counterpart of tumours. NAMPT inhibitors appear to have a role in hijacking myeloid-derived suppressor cell (MDSC) mobilization, activating antitumor immune responses and sensibilizing tumours to immune checkpoint inhibitors (Travelli et al., 2019b) as a result of a direct control of the microenvironment. No one has hypothesized this strategy in CRC, but it appears to be promising in CRCs with high immune infiltration or dependent on bowel inflammation (IBD-CRCs). This suggests that targeting iNAMPT in CRC could have a direct effect on tumours and an indirect anticancer activity on the immune system.

\section{Therapeutic role of NMNAT Targeting in Colorectal Cancer}

The final products of iNAMPT and NAPRT, NMN and nicotinic acid mononucleotide, are then transformed in NAD and nicotinic acid adenine dinucleotide (NAAD) through NMNAT, which is present in cells in three different isoforms (NMNAT1,2,3). NMNAT1 is predominantly present in the nucleus, NMNAT2 in the Golgi apparatus (Berger et al., 2005), while NMNAT3 in mitochondria or cytoplasm (Cambronne and Kraus, 2020). NMNAT2 has been highlighted as a possible diagnostic target for CRC, as its levels correlate with p53 in more invasive tumours, even though it is not correlated with overall survival (Cui et al., 2016). Furthermore, NMNAT2 overexpression in CRC is linked to SIRT6 downregulation (Qi et al., 2018).

It has been found that overexpression of NMNAT2 sensitises Caco-2 and HT-29 to tiazofurin, inducing cell death, while low level-NMNAT2 cell lines appear to be refractory (Kusumanchi et al., 2013). This is most likely due to a link between the amount of NAD and the presence of inosine monophosphate dehydrogenase (IMPD), the target of the active metabolite of tiazofurin, which is an NAD analogue. While NMNAT2 upregulation favours tiazofurin action, which were abandoned in clinics due to adverse events (Popsavin et al., 2006), it is thought that inhibitors of this enzyme would be a significantly better therapeutic option. Yet, at present no potent NMNAT inhibitor has been developed (Petrelli et al., 2011; Buonvicino et al., 2018), with the exception of 2,3-dibromo-1,4naphthoquinone (Haubrich et al., 2020), which nonetheless lacks selectivity against the different isoforms and possibly acts also on other targets. Yet, given the convergence of both iNAMPT and NAPRT on NMNAT2, it could be postulated that inhibitors of these isoform in CRC may be attractive.

\section{NICOTINAMIDE ADENINE DINUCLEOTIDE-UTILIZING ENZYMES AS DRUG TARGETS Therapeutic Role of Poly-ADP-Ribose Polymerase Inhibitors in Colorectal Cancer}

Increased production of ROS in cancer cells determines DNA damage, with base lesions or single strand breaks (Saikolappan et al., 2019; Chang et al., 2020). While some of these might lead to pro-tumoural permissive mutations, an excess would invariably lead to apoptosis. This balance is maintained by PARPs, an 18member nuclear enzyme family involved in DNA damage repair. PARPs orchestrate chromatin remodelling, transcription, replication, recombination and DNA repair (Morales et al., 2014) and are upregulated in CRC (Nosho et al., 2006; Dziaman et al., 2014). Of these 18 members, the most relevant ones in the context of cancer appear to be PARP1 and PARP2, recognized for their ability to activate base excision repair (BER) in response to single-stranded DNA breaks (SSBs). (Amé et al., 2004). Indeed, most tumours, to counterbalance ROS production, overexpress PARPs with the aim to increase genomic stability (Nomura et al., 2000). To support this, PARP-1 knock-out cells are more sensitive to exogenous DNA damage agents, such as alkylating drugs and irradiation (Menear et al., 2008). Briefly, in front of DNA damage response, there is the activation of several pathways that leads to poly ADP-ribosylation (PARylation) in the damage site by PARPs using NAD as a source of adenosine diphosphate ribose (ADPR).

Several PARP inhibitors have been developed and are already in the armamentarium of oncologists. Most of their indications at present pertain to patient populations (e.g., ovarian, breast, pancreatic, prostate cancer) in which there is a deficit of the BRCA1/2 genes, involved in homologous recombination and DNA repair, thereby providing an increased mutational burden that synergizes with PARP inhibition. Yet, in cancers in which BRCA1/2 is prevalent, PARP inhibitors have also shown an effect in the all-comer population. PARP inhibitors are increasing their importance in cancer therapy, and it is beyond the scope of the present manuscript to review them. It should be noticed, though, that although CRC is not yet an approved indication of any PARP inhibitor, several manuscripts have highlighted their potential, in particular in combination with DNA damaging agents such as irinotecan (Davidson et al., 2013; Genther Williams et al., 2015; Augustine et al., 2019), 5fluorouracil and oxaliplatin (Jarrar et al., 2019), PI3K inhibitors in combination with anti-CTLA4 immunotherapy and X-ray radiation (Landry et al., 2020), p53 inhibitors (idasanutlin or pifithirin- $\beta$ ) (Smeby et al., 2020) or ATM inhibitors (Wang et al., 
TABLE 1 | PARP inhibitors in different cell models.

\begin{tabular}{|c|c|c|c|}
\hline PARP inhibitor & Combinatory drug & Cell model & References \\
\hline Veliparib (ABT-888) & Irinotecan (SN-38) & HCT-116 & Davidson et al. (2013) \\
\hline Olaparib & ATM inhibitor (KU55933) & SK-CO-1 and HCT 116 & Wang et al. (2017b) \\
\hline Rucaparib & Irinotecan & HCT-116 & Augustine et al. (2019) \\
\hline Talazoparib, niraparib & Idasanutlin (MDM2i) and pifithrin- $\beta$ (p53i) & SK-CO-1, LS513, SW1222 and SNU61 & Smeby et al. (2020) \\
\hline Niraparib & $\mathrm{HS}-173(\mathrm{PI} 3 \mathrm{Ki}) \pm \gamma \mathrm{H} 2 \mathrm{AX}$ or $\alpha \mathrm{CTLA}-4$ & CT-26 & Landry et al. (2020) \\
\hline Niraparib & Irinotecan (SN-38) & Microsatellite stable/instable CRC cell lines & Genther Williams et al. (2015) \\
\hline Olaparib & 5-FU or oxalilplatin & CRC-patient-derived cell lines & Jarrar et al. (2019) \\
\hline
\end{tabular}

\begin{tabular}{|c|c|c|c|c|}
\hline $\begin{array}{l}\text { Study } \\
\text { number }\end{array}$ & Phase & Drugs & Enrolment & Ref/Stage \\
\hline NCT01051596 & 2 & Veliparib + temozolomide & 75 CRC patients incurable by surgery & $\begin{array}{l}\text { Completed (Pishvaian } \\
\text { et al., 2018) }\end{array}$ \\
\hline NCT00912743 & 2 & Olaparib & $33 \mathrm{CRC}$ patients incurable by surgery & $\begin{array}{l}\text { Completed (Leichman } \\
\text { et al., 2016) }\end{array}$ \\
\hline NCT02484404 & $1 / 2$ & Cediranib+Olaparib+MEDI4736 (anti-PD-L1) & $\begin{array}{l}\text { Phase } 2 \text { part of the study requests the participants to have } \\
\text { tumor samples removed }\end{array}$ & $\begin{array}{l}\text { Recruiting } \\
\text { (clinicaltrial.gov) }\end{array}$ \\
\hline NCT03875313 & $1 / 2$ & Talazoparib + telaglenastat (glutaminase inhibitor) & 33 between different types of solid tumour & $\begin{array}{l}\text { Terminated } \\
\text { (clinicaltrial.gov) }\end{array}$ \\
\hline NCT02305758 & 2 & Velparib + FOLFIRI + bevacizumab & 130 untreated metastatic colorectal cancer & $\begin{array}{l}\text { Completed } \\
\text { (Gorbunova et al., } \\
\text { 2019) }\end{array}$ \\
\hline NCT03337087 & $1 / 2$ & $\begin{array}{l}\text { 5-fluorouracil+leucovorin+liposomal irinotecan + } \\
\text { rucaparib }\end{array}$ & CRC (up to 3 lines of prior therapy) & $\begin{array}{l}\text { Recruiting } \\
\text { (clinicaltrial.gov) }\end{array}$ \\
\hline NCT03761914 & 2 & Olaparib+durvalumab & $\begin{array}{l}\text { Advanced Mismatch Repair Proficient Colorectal Cancer } \\
\text { (MMRp-CRC) }\end{array}$ & Active (clinicaltrial.gov) \\
\hline NCT04171700 & 2 & Rucaparib & $\begin{array}{l}\text { Mutations in Homologous Recombination Repair (HRR) } \\
\text { genes }\end{array}$ & $\begin{array}{l}\text { Recruiting } \\
\text { (clinicaltrial.gov) }\end{array}$ \\
\hline NCT01618136 & $1 / 2$ & $\begin{array}{l}\text { E7449 (PARP/tankyrase inhibitor) + temozolomide or } \\
\text { carboplatin and paclitaxel }\end{array}$ & 41 patients with solid tumours & $\begin{array}{l}\text { Completed (Plummer } \\
\text { et al., 2020) }\end{array}$ \\
\hline NCT00535353 & 1 & Olaparib + irinotecan hydrochloride & $\begin{array}{l}26 \text { patients with locally advanced or metastatic colorectal } \\
\text { cancer }\end{array}$ & $\begin{array}{l}\text { Completed (Chen } \\
\text { et al., 2016) }\end{array}$ \\
\hline NCT04456699 & 3 & Olaparib+bevacizumab & $\begin{array}{l}\text { Metastatic colorectal cancer (CRC) who have not progressed } \\
\text { following first-line induction of FOLFOX with bevacizumab }\end{array}$ & $\begin{array}{l}\text { Recruiting } \\
\text { (clinicaltrial.gov) }\end{array}$ \\
\hline NCT04166435 & 2 & Olaparib + temozolomide & $\begin{array}{l}\text { patients with MGMT promoter hypermethylated advanced } \\
\text { colorectal cancer }\end{array}$ & $\begin{array}{l}\text { Recruiting } \\
\text { (clinicaltrial.gov) }\end{array}$ \\
\hline
\end{tabular}

2017a). Mauri et al. have highlighted the "biomarkers of PARPness" which includes BRCA1/2 mutations in solid tumours, the sensitivity to platinum agents, but also ATM and CHK1 loss (Wang et al., 2017b; Mauri et al., 2020) (Table 1).

Different PARP inhibitors have already entered clinical trials in CRC (Table 2; clinicaltrials.gov). Several of them are still recruiting patients but others have already published encouraging results, despite the advanced settings. Pishvaian at al. have highlighted the efficient combination of veliparib and temozolomide in metastatic CRC population, refractory to other therapies, with a median OS of 6.6 months. More recently, Plummer et al. have demonstrated the efficacy of E7449 (PARP/tankyrase inhibitor) in patients with solid tumours, including $\mathrm{CRC}$, showing a promising antitumoral activity with $50-800 \mathrm{mg}$ oral dose. Furthermore, Chen et al. have evaluated that the combination of olaparib and irinotecan have appeared to be beneficial with intermittent administrations and dose reduction, avoiding side effects of both the molecules. On the other hand, Goburnova's and Leichman's groups have guided the only two terminated clinical trials in which, veliparib plus FOLFIRI and olaparib respectively, do not appear to be beneficial comparing to FOLFIRI alone or as a single agent. The conclusions of these studies are supported by the controlled nature of the trial, but both enrolled a very small number of patients in phase II trials. It is likely, therefore, that larger trials are needed to understand the potential of PARP inhibitors in CRC. For this to be successful, though, the correct patient population (in particular referring to the DNA repair machinery) and combination strategy should be optimized first.

\section{Therapeutic Role of Sirtuin Inhibitors in Colorectal Cancer}

Another class of NAD-consuming enzymes that has a role in genomic stability, metabolism and senescence are SIRT1-7 
TABLE 3 | SIRT properties in CRC.

\begin{tabular}{|c|c|c|c|}
\hline Isoform & Localization & Properties in CRC & Inhibitor \\
\hline $\mathrm{SIRT} 1$ & $\begin{array}{l}\text { Nucleus/Cytoplasm (O'Callaghan and } \\
\text { Vassilopoulos, 2017) }\end{array}$ & $\begin{array}{l}\text { Promotes EMT and metastasis formation (Cheng et al., } \\
\text { 2016) }\end{array}$ & $\begin{array}{l}\text { 4bb, evodiamine, MHY2256b (Ghosh et al., 2017; Zhou } \\
\text { et al., 2019; Kim et al., 2020) }\end{array}$ \\
\hline SIRT2 & $\begin{array}{l}\text { Cytoplasm/Nucleus (O'Callaghan and } \\
\text { Vassilopoulos, 2017) }\end{array}$ & Promotes tumour angiogenesis (Hu et al., 2018) & $\begin{array}{l}\text { MHY2256, AK-1, AF8, AF10, AF12 (Cheon et al., 2015; } \\
\text { Farooqi et al., 2019; Kim et al., 2020) }\end{array}$ \\
\hline SIRT3 & $\begin{array}{l}\text { Mitochondria (O'Callaghan and } \\
\text { Vassilopoulos, 2017) }\end{array}$ & $\begin{array}{l}\text { Modulates mitochondria fission, mobility and proliferation } \\
\text { (Wang et al., 2018a, 3) }\end{array}$ & 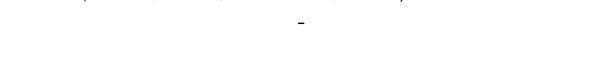 \\
\hline SIRT4 & $\begin{array}{l}\text { Mitochondria (O'Callaghan and } \\
\text { Vassilopoulos, 2017) }\end{array}$ & $\begin{array}{l}\text { Increased sensitivity to -FU (Huang et al., 2016) and } \\
\text { tumour-suppression (Miyo et al., 2015) }\end{array}$ & - \\
\hline SIRT5 & $\begin{array}{l}\text { Mitochondria/Cytoplasm (O'Callaghan } \\
\text { and Vassilopoulos, 2017) }\end{array}$ & - & - \\
\hline SIRT6 & $\begin{array}{l}\text { Nucleus (O’Callaghan and Vassilopoulos, } \\
\text { 2017) }\end{array}$ & Prognostic favourable (Zhang et al., 2019) & - \\
\hline SIRT7 & $\begin{array}{l}\text { Nucleus (O’Callaghan and Vassilopoulos, } \\
\text { 2017) }\end{array}$ & Radiosensitivity in CRC (Tang et al., 2017) & - \\
\hline
\end{tabular}

(Vassilopoulos et al., 2011). Sirtuins are class III histone deacetylase which are highly conserved and use NAD as an acetyl acceptor leading to O-acetyl-ADPR and free nicotinamide. While first described as histone deacetylates, these enzymes have multiple targets and is therefore not surprising that the different isoforms shown different subcellular localization: SIRT1, SIRT6 and SIRT7 are mostly localised in the nucleus; SIRT3, SIRT4 and SIRT5 are in mitochondria; while SIRT2 is restricted to the cytoplasm (O'Callaghan and Vassilopoulos, 2017). They exert different activities, summarized in Table 3. All the different isoforms have been studied as putative prognostic biomarkers in CRC, and some of them, as SIRT1 and 2 have been considered papabile targets (Huang et al., 2016; $\mathrm{Zu}$ et al., 2016).

Several sirtuin inhibitors have been developed through the years, but none has so far entered clinical trials for cancer. The most studied inhibitors developed are against SIRT1 and SIRT2. Ghosh et al. designed a SIRT1 inhibitor named $4 \mathrm{bb}$ which is able to induce HCT116 apoptosis via p53-acetylation and Bax and caspase overexpression (Ghosh et al., 2017). Moreover, also MHY2256, a SIRT1/2 inhibitor has been shown to reduce viability of both p53 wild-type or mutant colorectal cancer lines (HCT116, HT29 and DLD-1) (Kim et al., 2020). Given that SIRT2 is thought to promote vascular endothelial growth factor A (VEGF-A) signalling and endothelial-like tube formation in tumour angiogenesis ( $\mathrm{Hu}$ et al., 2018), specific inhibitors have also been developed. For example, AK-1, a cell-permeable benzylsulfonamide, is able to induce Snail down-regulation and the consequent block in G1phase of HCT116 cell line (Cheon et al., 2015), while several lysinebased thioureas named AF8, AF10 and AF12 are able to counteract viability in HCT116 cell line and in the xenograft murine model (Farooqi et al., 2019).

No other inhibitors have so far been tested in CRC, but it is possible that also other sirtuins might be promising therapeutic targets.

\section{Therapeutic role of CD38 Inhibitors/ Antibodies in Colorectal Cancer}

CD38 is an ADP-ribosyl glycohydrolase mainly expressed in hematopoietic and non-hematopoietic cells, orchestrating activation and differentiation. CD38 is a transmembrane protein, localised on the cell membrane endowed of both enzymatic and receptor activity. As an ectoenzyme, it promotes the catabolism of extracellular NAD and NADP into ADPR or, in smaller amounts and depending on $\mathrm{pH}$ conditions, into the $\mathrm{Ca} 2+-$ mediating second messengers cyclic adenosine diphosphate ribose (cADPR) and NAADP (van de Donk et al., 2018). The reaction produces CADPR, ADP ribose, and NAADP that stimulate Ca2+ mobilization (Malavasi et al., 2021). Whether in cancer biology this enzymatic activity is important has never been ascertained. On the other hand, as a receptor, CD38 is responsible of $\mathrm{T}$ cell activation, in particular in lamina propria cells, promoting colitis (Lischke et al., 2013) and it has been considered a positive prognostic marker for CRC (Perenkov et al., 2012).

Karakasheva et al. have highlighted that CD38 might be an interesting target for metastatic CRC. Using peripheral blood mononuclear cells (PBMCs) from CRC patients, compared to healthy donors, they observed an increased frequency of CD $38^{+}$ monocytic-myeloid-derived suppressor cells (M-MDSCs) and $\mathrm{CD}^{+} 8^{+}$ppolymorphonuclear-myeloid-derived suppressor cells (PMN-MDSCs) compared to healthy monocytes, with the ability to induce immunosuppressive properties (Karakasheva et al., 2018). Moreover, CD $38^{+} \mathrm{M}-\mathrm{MDSC}$ and CD $38^{+} \mathrm{PMN}-$ MDSCs of patients who have previously undergo treatment are increased compared to naïve patients. Other Authors have highlighted the promising use of anti-CD38 antibodies in CRC patients refractory to other therapies, nonetheless no clinical trials or approvals have been proposed for CRC, even though anti-CD38 antibodies have represented a break-through in multiple myeloma (Nooka et al., 2019) and are at present approved in this indication.

\section{Therapeutic Role of Aldehyde Dehydrogenases in Colorectal Cancer}

Among the different NAD-consuming enzyme, the aldehyde dehydrogenase (ALDHs) superfamily, composed by 19 different members, is known to be essential in the irreversible oxidation of a wide range of endo- and xenobiotic aldehydes to 
the respective carboxylic acid (Vassalli, 2019). Briefly, upon the activation of the catalytic cysteine (C302, numbering based on the ALDH2 sequence) by the glutamic acid (G268, numbering based on the ALDH2 sequence), the thiolate group interacts with the carbonyl carbon of the target aldehyde. After the deacylation, the hydride is transferred from the tetrahedral intermediate to the NAD pyridine ring. Finally, the thioester intermediate is hydrolysed, the reduced cofactor is dissociated and the enzyme can bind a new NAD molecule (Marchitti et al., 2008). The catalytic activity of ALDHs is essential to counterbalance the intrinsic toxicity of aldehydes, an extremely reactive chemical species extremely whose accumulation leads to DNA alkylation (LoPachin and Gavin, 2014). ALDHs are also involved in drug metabolism, and, for example, the active metabolite of cyclophosphamide, is a substrate of these enzymes (Tomita et al., 2016).

The relevance of this enzyme in the context of gastroenteric tumour is also given by the fact that CRCs are at times linked to high consumption of alcohol (Ferrari et al., 2012; Na and Lee, 2017). This could in part be attributable to acetaldehyde accumulation, produced by the alcohol oxidation (Zhang and $\mathrm{Fu}, 2021)$. Indeed, an unhealthy lifestyle with high alcohol consumption can be considered as one of the most common and important causes related to the potential development of CRCs and other significant cancers as head and neck, oesophageal and gastric (Zhang and Fu, 2021). Besides, a higher risk of CRCs has been demonstrated in Asian populations affected by a genetic polymorphism on the ALDH isoform 2, the key enzyme in acetaldehyde metabolism. The $A L D H 2 * 2$ allele is extremely common in Est Asians, with the glutamine 487 substituted by a lysine $(\mathrm{E} 487 \mathrm{~K})$ which intrinsic activity is reduced from 60 to 100\% (Chang et al., 2017; Rossi et al., 2018; Wang et al., 2018b). Based on these suggestions, a small molecule activator of the enzyme, known as alda-1, has been developed and characterized. This molecule increases the catalytic activity of wild-type ALDH2 just two-fold but increases 11-fold the activity of homozygous $\mathrm{ALDH}^{\star} 2$ (Chen et al., 2014). The high-resolution crystal structure of the ALDH2*2-Alda1 complex describes the peculiar mechanism of interaction in which the small ligands can reconstitute the correct folding at the level of the aG structure of the Rossman-fold essential for the interaction with the $\mathrm{NAD}^{+}$ adenosine ring and for the maintenance of the correct oligomerization, allowing the recovery of the full enzymatic activity (Perez-Miller et al., 2010).

Alongside activators in selected genetic contexts, inhibitors have also been proposed as possible therapeutics in CRC, due to an increased expression and activity of ALDHs (Khoury et al., 2012; Li et al., 2018; van der Waals et al., 2018; Yang et al., 2018; Attia et al., 2020). Interestingly, this is also true in the cancer stem cells (CSCs) (Clark and Palle, 2016), that are known as the most challenging to be targeted, refractory to common chemotherapeutics. It is also likely that this increased expression leads to chemotherapy and radiotherapy resistance of cancer cells and CSCs (Januchowski et al., 2013; Kim et al., 2017; Dinavahi et al., 2019; Muralikrishnan et al., 2020; Rebollido-Rios et al., 2020). ALDHs inhibitors have been proposed as monotherapies as well as in combination or as a tool for the early diagnosis (Koppaka et al., 2012; Anorma et al., 2018; Kim D. et al., 2018; Ferraris et al., 2020; Gelardi E. et al., 2021).

Among the 19 different isoforms, ALDH1A1 and 1A3, two key enzymes that participate in retinaldehyde oxidation (Moretti et al., 2016), have been scrutinized closely in several solid tumour, included the CRCs. Kovoska et al. have shown that abrogating $A L D H 1 A 3$ by siRNA-mediated gene silencing increases raltitrexed and 5-fluorouracil sensitivity of HCT-116 (Kozovska et al., 2018). Similarly, our group has recently described new ALDH1A3 inhibitors with a conserved imidazo [1,2- a]pyridine ring scaffold, considered as synthetic analogues of daidzin, a known reversible inhibitor of the ALDH isoenzymes (Quattrini et al., 2020b; Quattrini et al., 2020a). In particular one of the most promising compounds, called NR6, showed a strong potency and selectivity both against recombinant enzymes and cells overexpressing ALDH1A3 (Gelardi E. L. M. et al., 2021). The in vitro treatment with NR6 led to a strong cytotoxic effect only in cancer cell lines (HCT-116) overexpressing the target protein without inducing any significant toxicity in non-cancerous fibroblasts (CCD-18Co). The role of ALDH1A1 in CRCs is still unclear, outside the capacity to reduce the oxidative stress and the activity of alkylating agent, but it is considered as promising marker for the characterization of tumour malignancy and to locate the cancer stem cells (Ciccone et al., 2020). A small series of ALDH1A1 and ALDH1A pan-inhibitors are available, called CM10, A37 and NCT 501 hydrochloride (Morgan and Hurley, 2015; Yang et al., 2015; Chefetz et al., 2019) that were deeply investigated against ovarian cancer (Nwani et al., 2019), but that could be also useful to characterize the potential validity of ALDH1A1 as target in CRCs.

Another isoform that has gained interest in the past few years is mitochondrial ALDH1B1, the second most important enzyme in the alcohol metabolism, highly expressed in the crypts of intestinal tissues and a possible actor for tumour progression (Langan et al., 2012; Singh et al., 2015). Also in this case, immunohistochemistry experiments have shown a higher expression levels in cancer stem cells (Chen et al., 2011).

Taken together, these data suggest the relevance of this enzymatic superfamily as an intriguing and innovative target for cancer therapy, not only from the common perspective of the small inhibitor development but also as a marker for the early diagnosis.

\section{NADPH SYNTHESIS AS A TARGET}

As mentioned above, ROS production may determine DNA damage and apoptosis. Cancer cells have the ability to scavenge ROS formation by activating antioxidant mechanisms, but usually these require high NADPH levels (Ju et al., 2020). There are several mechanisms orchestrated by $\mathrm{NADPH}$ balance, including antioxidant reactions that lead to reduced glutathione, necessary for hydrogen peroxide reduction and fatty acids, amino acids and nucleotides synthesis able to promote tumour growth (Ju et al., 2020; Rather et al., 2021). Moreover, NADPH works as an essential electron donor and 


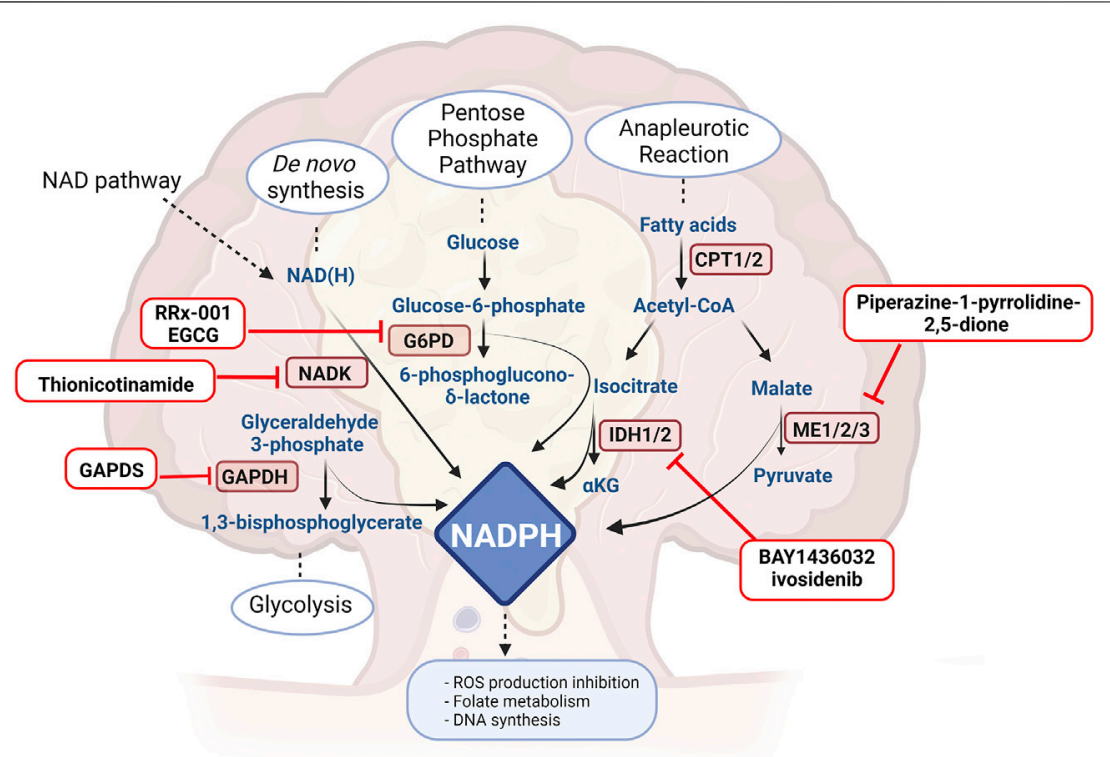

FIGURE 2 |Drugs or molecules that have been postulated as effective in CRC and that target NADPH routes. G6PH: glucose 6-phosphate dehydrogenase, NADK: NAD kinase, CPT: carnitine palmitoyl transferase, ME: malic enzyme, IDH: isocitrate dehydrogenase, GAPDH: glyceraldehyde 3-phosphate dehydrogenase. Created with BioRender.com.

cofactor maintaining reduction potential in anabolic reactions. In cancer cells, NADPH levels are controlled by several pathways, with the aim not only to contrast ROS production, but also in order to promote several metabolic reactions able to induce tumour proliferation, including NAD kinase (NADK), malic enzymes (ME) and NADP-dependent isocitrate dehydrogenases (IDH1 and IDH2) (Ju et al., 2020) but also glyceraldehyde 3-phosphate dehydrogenase (GAPDH). Also in this scenario, a number of agents have been developed and proposed to contrast NADPH homeostasis in cancer (Figure 2).

\section{Therapeutic Role of NADK Inhibitors in Colorectal Cancer}

De novo synthesis of NADPH is orchestrated by NADK, localised in mitochondria and in the cytosol, which phosphorylates NAD to NADP (Katsyuba et al., 2020; Pramono et al., 2020). Cytosolic NADK is overexpressed in several tumours, including colorectal cancer (Ju et al., 2020; Pramono et al., 2020). More importantly, cancer cells bear NADK mutations endowed of increase enzymatic activity, inducing higher production of NADPH and reduction of ROS, sustaining cancer cell viability (Tedeschi et al., 2016). It is well known that the silencing of NADK impairs cancer growth in human colorectal cancer (Tedeschi et al., 2015; Yau et al., 2017), but only one inhibitor has so far been described. Thionicotinamide, a structural analogue of $\mathrm{NAD}$, is able to counteract the growth of C85 (human colorectal cell line) both in vitro and in vivo, impairing the NADPH pool and augmenting ROS production (Tedeschi et al., 2015). The possibility to target only the mutated form of NADK is intriguing, but at present no specific inhibitor has been described.

\section{Therapeutic Role of Malic Enzymes in Colorectal Cancer}

Malic Enzymes contribute to both anabolic and catabolic reactions. They are tetrameric proteins with a double dimer structure, acting as oxidative decarboxylases. Malic enzymes are responsible for different actions which includes the decarboxylation of malate into pyruvate using NADP and producing NADPH, into Krebs cycle. Malic enzymes display different localisations: malic enzyme 1 (ME1) is in cytosol while malic enzyme 2 (ME2) and malic enzyme 3 (ME3) are located in mitochondria. ME1 participates in glycolysis and Krebs cycle but also in fatty acid and cholesterol synthesis using NADPH. ME1 produces NADPH stocked in the cytosol, which will be used by fatty acid synthase. (Fernandes et al., 2018).

Increased expression of MEs or increased activity has been associated to several types of cancer (Loeber et al., 1994; Ju et al., 2020) and all three isoforms have been associated with a worse prognosis in several type of cancer. In CRC, the literature has focused its attention on ME1, that, as other NADPH-dependent enzymes, also maintains the redox homeostasis in cells (Ju et al., 2020). Fernandez et al. have shown the importance of ME1 in the development of the tumoral mass in APCmin/+ mice. In detail, the number and the area of adenomas are increased in mice overexpressing ME1, which directly activates and sustains the Wnt/ $\beta$-catenin pathway. Moreover, silencing ME1 in several CRC cell lines determines cell death and senescence (Murai et al., 2017). Furthermore, using piperazine-1-pyrrolidine-2,5dione, a non-specific inhibitor (Zhang et al., 2006), they observed a decreased viability of HCT116 and HT29 treated or not in combination with a Wnt-canonical pathway inhibitor, confirming the potential of MEs as drug targets (Fernandes et al., 2018; Ju et al., 2020). 


\section{Therapeutic Role of G6PD in Colorectal Cancer}

The pentose phosphate pathway (PPP) is among the principal cellular NADPH suppliers. The PPP is divided into an oxidative branch in which glucose-6-phosphate dehydrogenase (G6PD) converts glucose-6-phosphate into pentose phosphate metabolites, synthetizing $\mathrm{NADPH}$, and in a non-oxidative branch that recycles pentose phosphates to glycolytic intermediates or produces ribose-5-phosphate (Boren et al., 2002). G6PD has been found over-expressed and overactivated in several cancers, determining poor prognosis and chemoresistance (Zhang et al., 2017; Yu et al., 2019; Ju et al., 2020), while its deficiency appears to decrease predisposition to cancer (Pes et al., 2019).

Several G6PD inhibitors have been developed. In CRC, RRx001 has been broadly studied (Reid et al., 2014; Oronsky et al., 2016). A comparative clinical trial in phase 2 (NCT02096354) is active comparing $\mathrm{RRx}-001$ in metastatic colorectal cancer in combination with irinotecan. Moreover, epicatechin gallate (EGCG), a putative G6PD inhibitor, has also been investigated in CRC, and has been shown to reduce the de novo synthesis of fatty acids and the pentose phosphate pathway in HT29 cells (Sánchez-Tena et al., 2013). EGCG has entered an early phase 1 clinical trial (NCT02891538) as chemo-preventive drug in patients who have undergone surgery and who do not require treatment after resection because of a benign prognosis.

\section{Therapeutic Role of Isocitrate Dehydrogenase in Colorectal Cancer}

Isocitrate dehydrogenase, an enzyme involved in TCA, synthetizes isocitrate from a-ketoglutarate, converting NADP to NADPH (Clark et al., 2016). It is present in three different isoforms: IDH1, situated in the cytosol and in peroxisomes, IDH2 and IDH3, which are located in mitochondria (Pramono et al., 2020). Both IDH1 and IDH2 are overexpressed in several types of tumours, decreasing ROS production and increasing concomitantly NADPH. Targeting IDH1 seems to be appealing in both wild-type and mutant forms. Indeed, IDH1 and IDH2 mutations occur in several tumours (Whitehall et al., 2014). In particular, the R132H IDH1 mutation lacks the classical enzymatic activity and is endowed of a particular synthetic pathway in which a-ketoglutarate is converted to 2hydroxyglutarate. 2-hydroxyglutarate appears to induce cell proliferation via the mTOR-signalling pathway (Neitzel et al., 2020) and increases lipogenesis during hypoxia (Reitman et al., 2014). The mutated IDH $1^{\mathrm{R} 132 \mathrm{H}}$ substantially decreases NADPH production (Bleeker et al., 2010). Tougeron et al. have not manged to observe IDH1/2 in CRC patients (Tougeron et al., 2016), while Whitehall et al. have underlined that these mutation are present in correspondence to the $\mathrm{CpG}$ island methylator phenotype and in the presence of BRAF mutations (Whitehall et al., 2014). The idea of targeting both the wild-type form or the mutated form appears to be beneficial in CRC (Neitzel et al., 2020). IDH1 mutations appear to be important also in IBD-CRCs where sporadic cancer gene mutations occur less often. In this case, targeted IDH therapy appears to be helpful (Alpert et al., 2019). Moreover, 2-hydroxyglutarate has been found elevated also in presence of wild-type IDH, in HCT116 and RKO cell lines, responsible of epithelial-mesenchymal transition and development of metastases (Fallah-Rad, 2016). On the other hand, wild-type IDH1 silencing determines NADPH reduction and the consequent sensibilization to chemotherapy (Ju et al., 2020), while HCT116 cell line, endowed of the mutated form, are more sensitive to cisplatin treatment, and this is reverted by AGI5198, an inhibitor of IDH1 mutated form (Khurshed et al., 2018). In contrast, the use of the IDH1 inhibitor BAY1436032 in mutant HCT116 (on R132H) leads to cell death (Pusch et al., 2017). Another important evidence is that the inhibitors of IDH mutated enzymes, as ML309 in combination with vitamin C, are responsible for the decrease of 2-hydroxyglutarate. This reduction determines an increase of DNA hydroxymethylation (Gerecke et al., 2020). What is also important is the posttranslational modifications on IDH1. Wang et al. have highlighted that IDH1 is hyperacetylated at lysine 224, promoting tumoral expansion and metastases, sign of poor prognosis. SIRT2 is responsible of the deacetylation of lys 224 in IDH1, increasing IDH1 enzymatic activity and reducing liver metastases (Wang et al., 2020). In conclusion, targeting mutated IDH in CRC seems to be appealing for IBD-CRCs, while in sporadic CRC wild-type IDH seems to be more plausible. Several mutant IDH1 inhibitors have entered clinical trials for hematologic malignancies (Rather et al., 2021), while only ivosidenib has been proposed as wild-type inhibitor in myeloid neoplasms (NCT03564821). The only clinical trial proposing IDH1 inhibitor for CRC is NCT04584008, aiming to use DNA sequencing in order to enrich patient populations with selected genotypes.

\section{Therapeutic Role of GADPH in Colorectal Cancer}

Glyceraldehyde 3-phosphate dehydrogenase is an enzyme that catalyses the sixth step of glycolysis and, surprisingly, is also a moonlighting protein, i.e., a protein that possesses other cellular functions alongside its prototypical one. Given the relevance in glycolytic metabolism it has obviously been linked to the energy metabolism of cancer cells. A genome-wide microarray analysis has revealed that GAPDH is highly expressed in rapidly proliferating colon cancer cells. Moreover, the glycolytic inhibition with $\mathrm{Na}$ iodoacetate promotes in vitro the reduction of growth of different colorectal cancer cells (Bazzocco et al., 2015) and the regression of xenograft tumours inducing necrosis (Sánchez-Aragó and Cuezva, 2011).

Given that GAPDH nitrosylation has been demonstrated to trigger nuclear translocation and initiate p53-mediated cell death (Hara et al., 2005), a recent article has provided the mechanism by which microcystins-LR (MC-LR), a toxin produced by cyanobacteria, induces colon cancer cells apoptosis. MC-LR cytotoxicity is associated with nitric oxide (NO) increases that induce GAPDH nitrosylation with the consequent nuclear translocation and colorectal cancer cell p53-mediated 
apoptosis (Li et al., 2020). Other evidence suggests that nuclear translocation of GAPDH increases under stressful stimuli. Grolla and collaborators have indeed demonstrated that GAPDH can be the shuttle for NAMPT from the cytosol in the nucleus under stress condition as oxidative stress, NO-induced stress and DNA damage to sustain the NMN/NAD pool (Grolla et al., 2016). Yet, the inhibitor of GAPDH shuttling to the nucleus, omigapil (Erb et al., 2009), has been evaluated in neurodegenerative disorders but has had little success in the cancer field.

Among several catalytic inhibitors, the triazine-based small molecule GAPDS has been reported to exert a specific anticancer activity in human carcinoma cells by preventing GAPDH tetramerization. GAPDS reduces cell viability in both normoxic and hypoxic conditions with an enhanced expression of apoptotic markers. Moreover, the effects on tetramerization result in a reduction in cytosolic GAPDH and tubulin expression which have a direct impact on the ability of cancer cells to invade and migrate (Jung et al., 2014). The involvement of GAPDH on cell motility has also been confirmed (Liu et al., 2017).

Studies on patient samples confirm the involvement of GAPDH in colorectal cancer. GAPDH mRNA levels were shown to have a 1.6-fold expression increase between normal and colorectal cancerous tissues and 2.3-fold expression comparing colorectal liver metastases and liver tissues (Rubie et al., 2005). A study on vitamin $\mathrm{C}$ on human colorectal cancer cells suggests that ROS are implicated in the mechanism by which vitamin $\mathrm{C}$ inhibits GAPDH. Vitamin C intracellular accumulation leads to the production of endogenous ROS, resulting in the reduction of GAPDH activity via posttranslational modifications and NAD depletion (Yun et al., 2015).

Despite one study shows a reduction of GAPDH expression in presence of metastasis (Tarrado-Castellarnau, 2017) some contrasting evidence also suggests a relationship between motility of cancer cells and this protein. Indeed, an increased expression of GAPDH in human colorectal cancer cells was associated with epithelial to mesenchymal transition (EMT) accompanied by the upregulation of mesenchymal markers (Liu et al., 2017). EMT is an important process involved in tumour invasion and metastasis formation and requires several regulators. The zinc-finger protein Snail binds to E-cadherin, suppresses the expression of the adhesion molecule and promotes the phenotypic transition (Cano et al., 2000). The silencing of GAPDH was shown to revert this phenomenon downregulating Snail expression associated with a reduction of vimentin and an increased expression of E-cadherin. Chromatin immunoprecipitation reveals that GAPDH physically interacts with the transcriptional factor Sp1 that binds to Snail promoting EMT (Liu et al., 2017). A recent study demonstrates the toxicity of a lipopeptidyl benzophene, asperphenin B, on human colorectal cancer cells associated with the downregulation of GAPDH expression. Moreover, GAPDH upregulation was found in metastasized cells and the anti-metastatic activity of the compound in vitro was correlated with the modulation of EMT signalling pathways (Byun et al., 2021).
GAPDH expression levels, considering all the stages of tumour progression, were not correlated with survival in patients with colorectal cancer (Tarrado-Castellarau, 2017) despite the evidence are not univocal.

Barbazán et al., have reported a multimarker expression panel of circulating tumour cells (CTC) to forecast prognosis in patients with metastatic colorectal cancer both at baseline and during treatment to monitor therapy response. GAPDH expression levels were included in the six-gene panel markers and Kaplan-Meier plots reveal an inverse correlation between high CTC group, progression-free survival and overall survival, elucidating an increased risk of tumour progression (Barbazán et al., 2014).

Therefore, GAPDH expression in colorectal cancer can contribute to highlight mechanisms involved in tumour progression and univocal data on patients will prompt the development of GAPDH targeted therapy in the clinical set.

\section{CONCLUSION}

The aim of this review was to understand how NAD and $\mathrm{NADPH}$ routes may be important in CRC progression, highlighting the enzymes that might represent pharmacological targets. NAD biosynthesis, the use of NAD as an ADPR donor and NADPH homeostasis are crucial for cellular metabolism and signalling. Not surprisingly, therefore, these pathways are upregulated in cancer, and this is true also for CRC. Yet, few of the players of the NADome have been investigated thoroughly in this setting, despite an important unmet therapeutic need. NAMPT and PARP at present appear to be the most promising targets. iNAMPT inhibitors have possibly been abandoned too early, for on target side effects, without giving enough emphasis on the identification of the patient population that might benefit more from these treatments, thereby generating a favourable benefit/risk. This may possibly be given by understanding how to determine the NAMPT-dependence of tumours. Moreover, the evidence on eNAMPT deriving from different settings support a potential beneficial effect of eNAMPT neutralization also in CRC.

PARP inhibitors have entered several clinical trials, primarily in combination. For some of the concluded trials, the combination of a PARP inhibitor with other molecules (e.g., irinotecan) appears to be therapeutically superior compared to classical alkylating agents, while the outcome of the other trials is awaited.

Last, the other NAD and NADPH routes targets reviewed by us appear to be either CRC markers or promoters of CRC progression. Yet, specific molecules to unravel their potential in CRC treatment have yet to be disclosed. SIRT, G6PD and ALDH inhibitors have never entered clinical trial, but their ability to contrast CRC development, as highlighted by our study, prompts the investigation of the molecules that will arise in this setting. Importantly, the innovative IDH inhibitor ivosidenib, that has a wild-type inhibitor active in myeloid neoplasms, may also be an alternative to be tested in IBDCRCs, where IDH is usually not mutated. 


\section{AUTHOR CONTRIBUTIONS}

GC and EG collected information and wrote the manuscript. FB and MM collected and analysed the information. GC, CT, and AG supervised the conception and writing of the manuscript.

\section{REFERENCES}

Abu Aboud, O., Chen, C. H., Senapedis, W., Baloglu, E., Argueta, C., and Weiss, R. H. (2016). Dual and Specific Inhibition of NAMPT and PAK4 by KPT-9274 Decreases Kidney Cancer Growth. Mol. Cancer Ther. 15, 2119-2129. doi:10.1158/1535-7163.MCT-16-0197

Alpert, L., Yassan, L., Poon, R., Kadri, S., Niu, N., Patil, S. A., et al. (2019). Targeted Mutational Analysis of Inflammatory Bowel Disease-Associated Colorectal Cancers. Hum. Pathol. 89, 44-50. doi:10.1016/j.humpath.2019.04.013

Amé, J. C., Spenlehauer, C., and de Murcia, G. (2004). The PARP Superfamily. Bioessays 26, 882-893. doi:10.1002/bies.20085

Anorma, C., Hedhli, J., Bearrood, T. E., Pino, N. W., Gardner, S. H., Inaba, H., et al. (2018). Surveillance of Cancer Stem Cell Plasticity Using an Isoform-Selective Fluorescent Probe for Aldehyde Dehydrogenase 1A1. ACS Cent. Sci. 4, 1045-1055. doi:10.1021/acscentsci.8b00313

Attia, Y. M., Hammam, O. A., Ammar, R. A., Mansour, M. T., and Elmazar, M. M. (2020). Crosstalk between Aldehyde Dehydrogenase-1 and Chemoresistance in Breast Cancer: Insights into the Role of Vitamin D3. Life Sci. 253, 117733. doi:10.1016/j.lfs.2020.117733

Audrito, V., Managò, A., Gaudino, F., Sorci, L., Messana, V. G., Raffaelli, N., et al. (2019). NAD-biosynthetic and Consuming Enzymes as Central Players of Metabolic Regulation of Innate and Adaptive Immune Responses in Cancer. Front. Immunol. 10, 1720. doi:10.3389/fimmu.2019.01720

Audrito, V., Serra, S., Brusa, D., Mazzola, F., Arruga, F., Vaisitti, T., et al. (2015). Extracellular Nicotinamide Phosphoribosyltransferase (NAMPT) Promotes M2 Macrophage Polarization in Chronic Lymphocytic Leukemia. Blood 125, 111-123. doi:10.1182/blood-2014-07-589069

Augustine, T., Maitra, R., Zhang, J., Nayak, J., and Goel, S. (2019). Sensitization of Colorectal Cancer to Irinotecan Therapy by PARP Inhibitor Rucaparib. Invest. New Drugs 37, 948-960. doi:10.1007/s10637-018-00717-9

Barbazán, J., Muinelo-Romay, L., Vieito, M., Candamio, S., Díaz-López, A., Cano, A., et al. (2014). A Multimarker Panel for Circulating Tumor Cells Detection Predicts Patient Outcome and Therapy Response in Metastatic Colorectal Cancer. Int. J. Cancer 135, 2633-2643. doi:10.1002/ijc.28910

Bazzocco, S., Dopeso, H., Carton-Garcia, F., Macaya, I., Andretta, E., Chionh, F., et al. (2015). Highly Expressed Genes in Rapidly Proliferating Tumor Cells as New Targets for Colorectal Cancer Treatment. Clin. Cancer Res. 21, 3695-3704. doi:10.1158/1078-0432.CCR-14-2457

Berger, F., Lau, C., Dahlmann, M., and Ziegler, M. (2005). Subcellular Compartmentation and Differential Catalytic Properties of the Three Human Nicotinamide Mononucleotide Adenylyltransferase Isoforms. J. Biol. Chem. 280, 36334-36341. doi:10.1074/jbc.M508660200

Bleeker, F. E., Atai, N. A., Lamba, S., Jonker, A., Rijkeboer, D., Bosch, K. S., et al. (2010). The Prognostic IDH1( R132 ) Mutation Is Associated with Reduced NADP+-dependent IDH Activity in Glioblastoma. Acta Neuropathol. 119, 487-494. doi:10.1007/s00401-010-0645-6

Boren, J., Montoya, A. R., de Atauri, P., Comin-Anduix, B., Cortes, A., Centelles, J. J., et al. (2002). Metabolic Control Analysis Aimed at the Ribose Synthesis Pathways of Tumor Cells: a New Strategy for Antitumor Drug Development. Mol. Biol. Rep. 29, 7-12. doi:10.1023/a:1020333730485

Brody, H. (2015). Colorectal Cancer. Nature 521, S1. doi:10.1038/521S1a

Buldak, R. J., Gowarzewski, M., Buldak, L., Skonieczna, M., Kukla, M., Polaniak, R., et al. (2015). Viability and Oxidative Response of Human Colorectal HCT-116 Cancer Cells Treated with visfatin/eNampt In Vitro. J. Physiol. Pharmacol. 66, 557-566.

Buonvicino, D., Mazzola, F., Zamporlini, F., Resta, F., Ranieri, G., Camaioni, E., et al. (2018). Identification of the Nicotinamide Salvage Pathway as a New

\section{FUNDING}

The research was supported by an AIRC grant to AG (AIRC IG 2018 21842), by a PRIN grant from the Italian Ministry of Health to AG (PRIN 2017 CBNCYT). AIRC fellowship to GC (Project Code: 25,323$)$.

Toxification Route for Antimetabolites. Cell Chem Biol 25, 471-e7. doi:10.1016/ j.chembiol.2018.01.012

Byun, W. S., Bae, E. S., Park, S. C., Kim, W. K., Shin, J., and Lee, S. K. (2021). Antitumor Activity of Asperphenin B by Induction of Apoptosis and Regulation of Glyceraldehyde-3-Phosphate Dehydrogenase in Human Colorectal Cancer Cells. J. Nat. Prod. 84, 683-693. doi:10.1021/ acs.jnatprod.0c01155

Cambronne, X. A., and Kraus, W. L. (2020). Location, Location, Location: Compartmentalization of NAD+ Synthesis and Functions in Mammalian Cells. Trends Biochem. Sci. 45, 858-873. doi:10.1016/ j.tibs.2020.05.010

Camp, S. M., Ceco, E., Evenoski, C. L., Danilov, S. M., Zhou, T., Chiang, E. T., et al. (2015). Unique Toll-like Receptor 4 Activation by NAMPT/PBEF Induces NFkB Signaling and Inflammatory Lung Injury. Sci. Rep. 5, 13135. doi:10.1038/ srep13135

Cano, A., Pérez-Moreno, M. A., Rodrigo, I., Locascio, A., Blanco, M. J., del Barrio, M. G., et al. (2000). The Transcription Factor Snail Controls EpithelialMesenchymal Transitions by Repressing E-Cadherin Expression. Nat. Cel Biol 2, 76-83. doi:10.1038/35000025

Chang, J. S., Hsiao, J. R., and Chen, C. H. (2017). ALDH2 Polymorphism and Alcohol-Related Cancers in Asians: a Public Health Perspective. J. Biomed. Sci. 24, 19. doi:10.1186/s12929-017-0327-y

Chang, M., Wang, H., Niu, J., Song, Y., and Zou, Z. (2020). Alkannin-Induced Oxidative DNA Damage Synergizes with PARP Inhibition to Cause Cancerspecific Cytotoxicity. Front. Pharmacol. 11, 610205. doi:10.3389/ fphar.2020.610205

Chefetz, I., Grimley, E., Yang, K., Hong, L., Vinogradova, E. V., Suciu, R., et al. (2019). A Pan-Aldh1a Inhibitor Induces Necroptosis in Ovarian Cancer Stemlike Cells. Cell Rep 26, 3061-e6. doi:10.1016/j.celrep.2019.02.032

Chen, C. H., Ferreira, J. C., Gross, E. R., and Mochly-Rosen, D. (2014). Targeting Aldehyde Dehydrogenase 2: New Therapeutic Opportunities. Physiol. Rev. 94, 1-34. doi:10.1152/physrev.00017.2013

Chen, E. X., Jonker, D. J., Siu, L. L., McKeever, K., Keller, D., Wells, J., et al. (2016). A Phase I Study of Olaparib and Irinotecan in Patients with Colorectal Cancer: Canadian Cancer Trials Group IND 187. Invest. New Drugs 34, 450-457. doi:10.1007/s10637-016-0351-x

Chen, Y., Orlicky, D. J., Matsumoto, A., Singh, S., Thompson, D. C., and Vasiliou, V. (2011). Aldehyde Dehydrogenase 1B1 (ALDH1B1) Is a Potential Biomarker for Human colon Cancer. Biochem. Biophys. Res. Commun. 405, 173-179. doi:10.1016/j.bbrc.2011.01.002

Cheng, F., Su, L., Yao, C., Liu, L., Shen, J., Liu, C., et al. (2016). SIRT1 Promotes Epithelial-Mesenchymal Transition and Metastasis in Colorectal Cancer by Regulating Fra-1 Expression. Cancer Lett. 375, 274-283. doi:10.1016/ j.canlet.2016.03.010

Cheon, M. G., Kim, W., Choi, M., and Kim, J. E. (2015). AK-1, a Specific SIRT2 Inhibitor, Induces Cell Cycle Arrest by Downregulating Snail in HCT116 Human colon Carcinoma Cells. Cancer Lett. 356, 637-645. doi:10.1016/ j.canlet.2014.10.012

Chiarugi, A., Dölle, C., Felici, R., and Ziegler, M. (2012). The NAD Metabolome-Aa Key Determinant of Cancer Cell Biology. Nat. Rev. Cancer 12, 741-752. doi:10.1038/nrc3340

Chowdhry, S., Zanca, C., Rajkumar, U., Koga, T., Diao, Y., Raviram, R., et al. (2019). NAD Metabolic Dependency in Cancer Is Shaped by Gene Amplification and Enhancer Remodelling. Nature 569, 570-575. doi:10.1038/s41586-019-1150-2

Ciccone, V., Morbidelli, L., Ziche, M., and Donnini, S. (2020). How to Conjugate the Stemness Marker ALDH1A1 with Tumor Angiogenesis, Progression, and Drug Resistance. Cdr 3, 26-37. doi:10.20517/cdr.2019.70 
Clark, D. W., and Palle, K. (2016). Aldehyde Dehydrogenases in Cancer Stem Cells: Potential as Therapeutic Targets. Ann. Transl Med. 4, 518. doi:10.21037/ atm.2016.11.82

Clark, O., Yen, K., and Mellinghoff, I. K. (2016). Molecular Pathways: Isocitrate Dehydrogenase Mutations in Cancer. Clin. Cancer Res. 22, 1837-1842. doi:10.1158/1078-0432.CCR-13-1333

Cole, J., Guiot, M. C., Gravel, M., Bernier, C., Shore, G. C., and Roulston, A. (2017). Novel NAPRT Specific Antibody Identifies Small Cell Lung Cancer and Neuronal Cancers as Promising Clinical Indications for a NAMPT Inhibitor/niacin Co-administration Strategy. Oncotarget 8, 77846-77859. doi:10.18632/oncotarget.20840

Colombo, G., Clemente, N., Zito, A., Bracci, C., Colombo, F. S., Sangaletti, S., et al. (2020). Neutralization of Extracellular NAMPT (Nicotinamide Phosphoribosyltransferase) Ameliorates Experimental Murine Colitis. J. Mol. Med. 98, 595-612. doi:10.1007/s00109-020-01892-0

Cui, C., Qi, J., Deng, Q., Chen, R., Zhai, D., and Yu, J. (2016). Nicotinamide Mononucleotide Adenylyl Transferase 2: A Promising Diagnostic and Therapeutic Target for Colorectal Cancer. Biomed. Res. Int. 2016, 1804137. doi:10.1155/2016/1804137

Davidson, D., Wang, Y., Aloyz, R., and Panasci, L. (2013). The PARP Inhibitor ABT-888 Synergizes Irinotecan Treatment of colon Cancer Cell Lines. Invest. New Drugs 31, 461-468. doi:10.1007/s10637-012-9886-7

Dinavahi, S. S., Bazewicz, C. G., Gowda, R., and Robertson, G. P. (2019). Aldehyde Dehydrogenase Inhibitors for Cancer Therapeutics. Trends Pharmacol. Sci. 40, 774-789. doi:10.1016/j.tips.2019.08.002

Duarte-Pereira, S., Pereira-Castro, I., Silva, S. S., Correia, M. G., Neto, C., da Costa, L. T., et al. (2016). Extensive Regulation of Nicotinate Phosphoribosyltransferase (NAPRT) Expression in Human Tissues and Tumors. Oncotarget 7, 1973-1983. doi:10.18632/oncotarget.6538

Dziaman, T., Ludwiczak, H., Ciesla, J. M., Banaszkiewicz, Z., Winczura, A., Chmielarczyk, M., et al. (2014). PARP-1 Expression Is Increased in Colon Adenoma and Carcinoma and Correlates with OGG1. PLOS ONE 9, e115558. doi:10.1371/journal.pone.0115558

Erb, M., Meinen, S., Barzaghi, P., Sumanovski, L. T., Courdier-Früh, I., Rüegg, M. A., et al. (2009). Omigapil Ameliorates the Pathology of Muscle Dystrophy Caused by Laminin-Alpha2 Deficiency. J. Pharmacol. Exp. Ther. 331, 787-795. doi:10.1124/jpet.109.160754

Fallah-Rad, N. (2016). Association of Isocitrate Dehydorgenase-1 (IDH-1) Mutations with Elevated Oncometabolite 2-hydroxyglutarate (2HG) in Advanced Colorectal Cancer. | J. Clin. Oncol.. Available at: https://ascopubs.org/doi/abs/10.1200/jco.2016. 34.4_suppl.627 [Accessed July 27, 2021].doi:10.1200/jco.2016.34.4_suppl.627

Farooqi, A. S., Hong, J. Y., Cao, J., Lu, X., Price, I. R., Zhao, Q., et al. (2019). Novel LysineBased Thioureas as Mechanism-Based Inhibitors of Sirtuin 2 (SIRT2) with Anticancer Activity in a Colorectal Cancer Murine Model. J. Med. Chem. 62, 4131-4141. doi:10.1021/acs.jmedchem.9b00191

Fernandes, L. M., Al-Dwairi, A., Simmen, R. C. M., Marji, M., Brown, D. M., Jewell, S. W., et al. (2018). Malic Enzyme 1 (ME1) Is Pro-oncogenic in ApcMin/+ Mice. Sci. Rep. 8, 14268. doi:10.1038/s41598-018-32532-w

Ferrari, P., McKay, J. D., Jenab, M., Brennan, P., Canzian, F., Vogel, U., et al. (2012). Alcohol Dehydrogenase and Aldehyde Dehydrogenase Gene Polymorphisms, Alcohol Intake and the Risk of Colorectal Cancer in the European Prospective Investigation into Cancer and Nutrition Study. Eur. J. Clin. Nutr. 66, 1303-1308. doi:10.1038/ejcn.2012.173

Ferraris, D. M., Gelardi, E. L. M., Garavaglia, S., Miggiano, R., and Rizzi, M. (2020). Targeting NAD-dependent Dehydrogenases in Drug Discovery against Infectious Diseases and Cancer. Biochem. Soc. Trans. 48, 693-707. doi:10.1042/BST20191261

Galli, U., Colombo, G., Travelli, C., Tron, G. C., Genazzani, A. A., and Grolla, A. A. (2020). Recent Advances in NAMPT Inhibitors: A Novel Immunotherapic Strategy. Front. Pharmacol. 11, 656. doi:10.3389/fphar.2020.00656

Garcia, A. N., Casanova, N. G., Valera, D. G., Sun, X., Song, J. H., Kempf, C. L., et al. (2021). Involvement of eNAMPT/TLR4 Signaling in Murine Radiation Pneumonitis: protection by eNAMPT Neutralization. Translational Res. S1931-5244 (21), 00141-00149. doi:10.1016/j.trsl.2021.06.002

Gelardi, E., Caprioglio, D., Colombo, G., Mazzoletti, D., Mattoteia, D., Salamone, S., et al. (2021a). Curcumin-based-fluorescent Probes Targeting ALDH1A3 as a Promising Tool for Glioblastoma Precision Surgery and Early Diagnosis. doi: doi:10.21203/rs.3.rs-567295/v1
Gelardi, E. L. M., Colombo, G., Picarazzi, F., Ferraris, D. M., Mangione, A., Petrarolo, G., et al. (2021b). A Selective Competitive Inhibitor of Aldehyde Dehydrogenase 1A3 Hinders Cancer Cell Growth, Invasiveness and Stemness In Vitro. Cancers 13, 356. doi:10.3390/cancers 13020356

Genther Williams, S. M., Kuznicki, A. M., Andrade, P., Dolinski, B. M., Elbi, C., O'Hagan, R. C., et al. (2015). Treatment with the PARP Inhibitor, Niraparib, Sensitizes Colorectal Cancer Cell Lines to Irinotecan Regardless of MSI/MSS Status. Cancer Cel Int 15, 14. doi:10.1186/s12935-015-0162-8

Gerecke, C., Schumacher, F., Berndzen, A., Homann, T., and Kleuser, B. (2020). Vitamin C in Combination with Inhibition of Mutant IDH1 Synergistically Activates TET Enzymes and Epigenetically Modulates Gene Silencing in colon Cancer Cells. Epigenetics 15, 307-322. doi:10.1080/ 15592294.2019.1666652

Ghosh, A., Sengupta, A., Seerapu, G. P. K., Nakhi, A., Shivaji Ramarao, E. V. V., Bung, N., et al. (2017). A Novel SIRT1 Inhibitor, 4bb Induces Apoptosis in HCT116 Human colon Carcinoma Cells Partially by Activating P53. Biochem. Biophys. Res. Commun. 488, 562-569. doi:10.1016/j.bbrc.2017.05.089

Goldinger, S. M., Gobbi Bischof, S., Fink-Puches, R., Klemke, C. D., Dréno, B., Bagot, M., et al. (2016). Efficacy and Safety of APO866 in Patients with Refractory or Relapsed Cutaneous T-Cell Lymphoma: A Phase 2 Clinical Trial. JAMA Dermatol. 152, 837-839. doi:10.1001/jamadermatol.2016.0401

Gorbunova, V., Beck, J. T., Hofheinz, R. D., Garcia-Alfonso, P., Nechaeva, M., Gracian, A. C., et al. (2019). Correction: A Phase 2 Randomised Study of Veliparib Plus FOLFIRI \pm bevacizumab versus Placebo Plus FOLFIRI \pm bevacizumab in Metastatic Colorectal Cancer. Br. J. Cancer 121, 429-430. doi:10.1038/s41416-019-0528-0

Grasmann, G., Smolle, E., Olschewski, H., and Leithner, K. (20191872). Gluconeogenesis in Cancer Cells - Repurposing of a Starvation-Induced Metabolic Pathway?. Biochim. Biophys. Acta Rev. Cancer 1872, 24-36. doi:10.1016/j.bbcan.2019.05.006

Grolla, A. A., Travelli, C., Genazzani, A. A., and Sethi, J. K. (2016). Extracellular Nicotinamide Phosphoribosyltransferase, a New Cancer Metabokine. Br. J. Pharmacol. 173, 2182-2194. doi:10.1111/bph.13505

Hara, M. R., Agrawal, N., Kim, S. F., Cascio, M. B., Fujimuro, M., Ozeki, Y., et al. (2005). S-nitrosylated GAPDH Initiates Apoptotic Cell Death by Nuclear Translocation Following Siah1 Binding. Nat. Cel Biol 7, 665-674. doi: $10.1038 /$ ncb1268

Hara, N., Yamada, K., Shibata, T., Osago, H., Hashimoto, T., and Tsuchiya, M. (2007). Elevation of Cellular NAD Levels by Nicotinic Acid and Involvement of Nicotinic Acid Phosphoribosyltransferase in Human Cells. J. Biol. Chem. 282, 24574-24582. doi:10.1074/jbc.M610357200

Haubrich, B. A., Ramesha, C., and Swinney, D. C. (2020). Development of a Bioluminescent High-Throughput Screening Assay for Nicotinamide Mononucleotide Adenylyltransferase (NMNAT). SLAS Discov. 25, 33-42. doi:10.1177/2472555219879644

Holen, K., Saltz, L. B., Hollywood, E., Burk, K., and Hanauske, A. R. (2008). The Pharmacokinetics, Toxicities, and Biologic Effects of FK866, a Nicotinamide Adenine Dinucleotide Biosynthesis Inhibitor. Invest. New Drugs 26, 45-51. doi:10.1007/s10637-007-9083-2

Hong, S. M., Hwang, S. W., Wang, T., Park, C. W., Ryu, Y. M., Jung, J. H., et al. (2019). Increased Nicotinamide Adenine Dinucleotide Pool Promotes colon Cancer Progression by Suppressing Reactive Oxygen Species Level. Cancer Sci. 110, 629-638. doi:10.1111/cas.13886

Hu, F., Sun, X., Li, G., Wu, Q., Chen, Y., Yang, X., et al. (2018). Inhibition of SIRT2 Limits Tumour Angiogenesis via Inactivation of the STAT3/VEGFA Signalling Pathway. Cell Death Dis 10, 9. doi:10.1038/s41419-018-1260-z

Huang, G., Cheng, J., Yu, F., Liu, X., Yuan, C., Liu, C., et al. (2016). Clinical and Therapeutic Significance of Sirtuin-4 Expression in Colorectal Cancer. Oncol. Rep. 35, 2801-2810. doi:10.3892/or.2016.4685

Januchowski, R., Wojtowicz, K., and Zabel, M. (2013). The Role of Aldehyde Dehydrogenase (ALDH) in Cancer Drug Resistance. Biomed. Pharmacother. 67, 669-680. doi:10.1016/j.biopha.2013.04.005

Jarrar, A., Lotti, F., DeVecchio, J., Ferrandon, S., Gantt, G., Mace, A., et al. (2019). Poly(ADP-Ribose) Polymerase Inhibition Sensitizes Colorectal CancerInitiating Cells to Chemotherapy. Stem Cells 37, 42-53. doi:10.1002/stem.2929

Ju, H. Q., Lin, J. F., Tian, T., Xie, D., and Xu, R. H. (2020). NADPH Homeostasis in Cancer: Functions, Mechanisms and Therapeutic Implications. Signal. Transduct Target. Ther. 5, 231. doi:10.1038/s41392-020-00326-0 
Jung, D. W., Kim, W. H., Seo, S., Oh, E., Yim, S. H., Ha, H. H., et al. (2014). Chemical Targeting of GAPDH Moonlighting Function in Cancer Cells Reveals its Role in Tubulin Regulation. Chem. Biol. 21, 1533-1545. doi:10.1016/ j.chembiol.2014.08.017

Karakasheva, T. A., Dominguez, G. A., Hashimoto, A., Lin, E. W., Chiu, C., Sasser, K., et al. (2018). CD38+ M-MDSC Expansion Characterizes a Subset of Advanced Colorectal Cancer Patients. JCI Insight 3, 97022. doi:10.1172/ jci.insight.97022

Katsyuba, E., Romani, M., Hofer, D., and Auwerx, J. (2020). NAD+ Homeostasis in Health and Disease. Nat. Metab. 2, 9-31. doi:10.1038/s42255-019-0161-5

Khoury, T., Ademuyiwa, F. O., Chandrasekhar, R., Chandraseekhar, R., Jabbour, M., Deleo, A., et al. (2012). Aldehyde Dehydrogenase 1A1 Expression in Breast Cancer Is Associated with Stage, Triple Negativity, and Outcome to Neoadjuvant Chemotherapy. Mod. Pathol. 25, 388-397. doi:10.1038/ modpathol.2011.172

Khurshed, M., Aarnoudse, N., Hulsbos, R., Hira, V. V. V., Laarhoven, H. W. M., Wilmink, J. W., et al. (2018). IDH1-mutant Cancer Cells Are Sensitive to Cisplatin and an IDH1-mutant Inhibitor Counteracts This Sensitivity. FASEB j. 32-63526344. doi:10.1096/fj.201800547R

Kim, D., Choi, B. H., Ryoo, I. G., and Kwak, M. K. (2018a). High NRF2 Level Mediates Cancer Stem Cell-like Properties of Aldehyde Dehydrogenase (ALDH)-high Ovarian Cancer Cells: Inhibitory Role of All-Trans Retinoic Acid in ALDH/NRF2 Signaling. Cel Death Dis 9, 335-342. doi:10.1038/s41419018-0903-4

Kim, H. I., Lim, H., and Moon, A. (2018b). Sex Differences in Cancer: Epidemiology, Genetics and Therapy. Biomol. Ther. (Seoul) 26, 335-342. doi:10.4062/biomolther.2018.103

Kim, J., Shin, J. H., Chen, C. H., Cruz, L., Farnebo, L., Yang, J., et al. (2017). Targeting Aldehyde Dehydrogenase Activity in Head and Neck Squamous Cell Carcinoma with a Novel Small Molecule Inhibitor. Oncotarget 8, 52345-52356. doi:10.18632/oncotarget.17017

Kim, M. J., Kang, Y. J., Sung, B., Jang, J. Y., Ahn, Y. R., Oh, H. J., et al. (2020). Novel SIRT Inhibitor, MHY2256, Induces Cell Cycle Arrest, Apoptosis, and Autophagic Cell Death in HCT116 Human Colorectal Cancer Cells. Biomol. Ther. (Seoul) 28, 561-568. doi:10.4062/biomolther.2020.153

Koppaka, V., Thompson, D. C., Chen, Y., Ellermann, M., Nicolaou, K. C., Juvonen, R. O., et al. (2012). Aldehyde Dehydrogenase Inhibitors: a Comprehensive Review of the Pharmacology, Mechanism of Action, Substrate Specificity, and Clinical Application. Pharmacol. Rev. 64, 520-539. doi:10.1124/pr.111.005538

Koyanagi, K., Bilchik, A. J., Saha, S., Turner, R. R., Wiese, D., McCarter, M., et al. (2008). Prognostic Relevance of Occult Nodal Micrometastases and Circulating Tumor Cells in Colorectal Cancer in a Prospective Multicenter Trial. Clin. Cancer Res. 14, 7391-7396. doi:10.1158/1078-0432.CCR-08-0290

Kozovska, Z., Patsalias, A., Bajzik, V., Durinikova, E., Demkova, L., Jargasova, S., et al. (2018). ALDH1A Inhibition Sensitizes colon Cancer Cells to Chemotherapy. BMC Cancer 18, 656. doi:10.1186/s12885-018-4572-6

Kusumanchi, P., Zhang, Y., Jani, M. B., Jayaram, N. H., Khan, R. A., Tang, Y., et al. (2013). Nicotinamide Mononucleotide Adenylyltransferase2 Overexpression Enhances Colorectal Cancer Cell-Kill by Tiazofurin. Cancer Gene Ther. 20, 403-412. doi:10.1038/cgt.2013.33

La Vecchia, S., and Sebastián, C. (2020). Metabolic Pathways Regulating Colorectal Cancer Initiation and Progression. Semin. Cel Dev Biol 98, 63-70. doi:10.1016/ j.semcdb.2019.05.018

Landry, M. R., DuRoss, A. N., Neufeld, M. J., Hahn, L., Sahay, G., Luxenhofer, R., et al. (2020). Low Dose Novel PARP-Pi3k Inhibition via Nanoformulation Improves Colorectal Cancer Immunoradiotherapy. Mater. Today Bio 8, 100082. doi:10.1016/j.mtbio.2020.100082

Langan, R. C., Mullinax, J. E., Ray, S., Raiji, M. T., Schaub, N., Xin, H. W., et al. (2012). A Pilot Study Assessing the Potential Role of Non-cd133 Colorectal Cancer Stem Cells as Biomarkers. J. Cancer 3, 231-240. doi:10.7150/jca.4542

Leichman, L., Groshen, S., O’Neil, B. H., Messersmith, W., Berlin, J., Chan, E., et al. (2016). Phase II Study of Olaparib (AZD-2281) after Standard Systemic Therapies for Disseminated Colorectal Cancer. Oncologist 21, 172-177. doi:10.1634/theoncologist.2015-0319

Li, G., Li, Y., Liu, X., Wang, Z., Zhang, C., Wu, F., et al. (2018). ALDH1A3 Induces Mesenchymal Differentiation and Serves as a Predictor for Survival in Glioblastoma. Cel Death Dis 9, 1190-1211. doi:10.1038/s41419-018-1232-3
Li, K., Huang, M., Xu, P., Wang, M., Ye, S., Wang, Q., et al. (2020). Microcystins-LR Induced Apoptosis via S-Nitrosylation of GAPDH in Colorectal Cancer Cells. Ecotoxicol Environ. Saf. 190, 110096. doi:10.1016/j.ecoenv.2019.110096

Lischke, T., Schumacher, V., Wesolowski, J., Hurwitz, R., Haag, F., Koch-Nolte, F., et al. (2013). CD8- $\beta$ ADP-Ribosylation Affects CD8(+) T-Cell Function. Eur. J. Immunol. 43, 1828-1838. doi:10.1002/eji.201243231

Liu, K., Tang, Z., Huang, A., Chen, P., Liu, P., Yang, J., et al. (2017). Glyceraldehyde-3-phosphate Dehydrogenase Promotes Cancer Growth and Metastasis through Upregulation of SNAIL Expression. Int. J. Oncol. 50, 252-262. doi:10.3892/ijo.2016.3774

Loeber, G., Dworkin, M. B., Infante, A., and Ahorn, H. (1994). Characterization of Cytosolic Malic Enzyme in Human Tumor Cells. FEBS Lett. 344, 181-186. doi:10.1016/0014-5793(94)00386-6

LoPachin, R. M., and Gavin, T. (2014). Molecular Mechanisms of Aldehyde Toxicity: a Chemical Perspective. Chem. Res. Toxicol. 27, 1081-1091. doi:10.1021/tx5001046

Loree, J. M., and Kopetz, S. (2017). Recent Developments in the Treatment of Metastatic Colorectal Cancer. Ther. Adv. Med. Oncol. 9, 551-564. doi:10.1177/ 1758834017714997

Lucena-Cacace, A., Otero-Albiol, D., Jiménez-García, M. P., Muñoz-Galvan, S., and Carnero, A. (2018). NAMPT Is a Potent Oncogene in Colon Cancer Progression that Modulates Cancer Stem Cell Properties and Resistance to Therapy through Sirt1 and PARP. Clin. Cancer Res. 24, 1202-1215. doi:10.1158/1078-0432.CCR-17-2575

Lv, X., Zhang, L., Zhu, Y., Said, H. M., Shi, J., and Xu, G. (2015). Regulative Effect of Nampt on Tumor Progression and Cell Viability in Human Colorectal Cancer. J. Cancer 6, 849-858. doi:10.7150/jca.12341

Malavasi, F., Faini, A. C., Morandi, F., Castella, B., Incarnato, D., Oliviero, S., et al. (2021). Molecular Dynamics of Targeting CD38 in Multiple Myeloma. Br. J. Haematol. 193, 581-591. doi:10.1111/bjh.17329

Managò, A., Audrito, V., Mazzola, F., Sorci, L., Gaudino, F., Gizzi, K., et al. (2019). Extracellular Nicotinate Phosphoribosyltransferase Binds Toll like Receptor 4 and Mediates Inflammation. Nat. Commun. 10, 4116. doi:10.1038/s41467-01912055-2

Marchitti, S. A., Brocker, C., Stagos, D., and Vasiliou, V. (2008). Non-P450 Aldehyde Oxidizing Enzymes: the Aldehyde Dehydrogenase Superfamily. Expert Opin. Drug Metab. Toxicol. 4, 697-720. doi:10.1517/17425255.4.6.697

Mauri, G., Arena, S., Siena, S., Bardelli, A., and Sartore-Bianchi, A. (2020). The DNA Damage Response Pathway as a Land of Therapeutic Opportunities for Colorectal Cancer. Ann. Oncol. 31, 1135-1147. doi:10.1016/ j.annonc.2020.05.027

Menear, K. A., Adcock, C., Boulter, R., Cockcroft, X. L., Copsey, L., Cranston, A., et al. (2008). 4-[3-(4-cyclopropanecarbonylpiperazine-1-carbonyl)-4fluorobenzyl]-2H-phthalazin-1-one: a Novel Bioavailable Inhibitor of poly(ADP-Ribose) Polymerase-1. J. Med. Chem. 51, 6581-6591. doi:10.1021/ jm8001263

Miyo, M., Yamamoto, H., Konno, M., Colvin, H., Nishida, N., Koseki, J., et al. (2015). Tumour-suppressive Function of SIRT4 in Human Colorectal Cancer. Br. J. Cancer 113, 492-499. doi:10.1038/bjc.2015.226

Morales, J., Li, L., Fattah, F. J., Dong, Y., Bey, E. A., Patel, M., et al. (2014). Review of Poly (ADP-Ribose) Polymerase (PARP) Mechanisms of Action and Rationale for Targeting in Cancer and Other Diseases. Crit. Rev. Eukaryot. Gene Expr. 24, 15-28. doi:10.1615/ critreveukaryotgeneexpr.2013006875

Moretti, A., Li, J., Donini, S., Sobol, R. W., Rizzi, M., and Garavaglia, S. (2016). Crystal Structure of Human Aldehyde Dehydrogenase 1A3 Complexed with NAD+ and Retinoic Acid. Sci. Rep. 6, 35710. doi:10.1038/srep35710

Morgan, C. A., and Hurley, T. D. (2015). Characterization of Two Distinct Structural Classes of Selective Aldehyde Dehydrogenase 1A1 Inhibitors. J. Med. Chem. 58, 1964-1975. doi:10.1021/jm501900s

Murai, S., Ando, A., Ebara, S., Hirayama, M., Satomi, Y., and Hara, T. (2017). Inhibition of Malic Enzyme 1 Disrupts Cellular Metabolism and Leads to Vulnerability in Cancer Cells in Glucose-Restricted Conditions. Oncogenesis 6, e329. doi:10.1038/oncsis.2017.34

Muralikrishnan, V., Hurley, T. D., and Nephew, K. P. (2020). Targeting Aldehyde Dehydrogenases to Eliminate Cancer Stem Cells in Gynecologic Malignancies. Cancers (Basel) 12, E961. doi:10.3390/cancers12040961 
Na, H. K., and Lee, J. Y. (2017). Molecular Basis of Alcohol-Related Gastric and Colon Cancer. Int. J. Mol. Sci. 18, E1116. doi:10.3390/ijms18061116

Nakajima, T. E., Yamada, Y., Hamano, T., Furuta, K., Matsuda, T., Fujita, S., et al. (2010). Adipocytokines as New Promising Markers of Colorectal Tumors: Adiponectin for Colorectal Adenoma, and Resistin and Visfatin for Colorectal Cancer. Cancer Sci. 101, 1286-1291. doi:10.1111/j.13497006.2010.01518.x

Neitzel, C., Demuth, P., Wittmann, S., and Fahrer, J. (2020). Targeting Altered Energy Metabolism in Colorectal Cancer: Oncogenic Reprogramming, the Central Role of the TCA Cycle and Therapeutic Opportunities. Cancers (Basel) 12, E1731. doi:10.3390/cancers12071731

Nomura, F., Yaguchi, M., Togawa, A., Miyazaki, M., Isobe, K., Miyake, M., et al. (2000). Enhancement of Poly-Adenosine Diphosphate-Ribosylation in Human Hepatocellular Carcinoma. J. Gastroenterol. Hepatol. 15, 529-535. doi:10.1046/ j.1440-1746.2000.02193.x

Nooka, A. K., Kaufman, J. L., Hofmeister, C. C., Joseph, N. S., Heffner, T. L., Gupta, V. A., et al. (2019). Daratumumab in Multiple Myeloma. Cancer 125, 2364-2382. doi:10.1002/cncr.32065

Nosho, K., Yamamoto, H., Mikami, M., Taniguchi, H., Takahashi, T., Adachi, Y., et al. (2006). Overexpression of poly(ADP-Ribose) Polymerase-1 (PARP-1) in the Early Stage of Colorectal Carcinogenesis. Eur. J. Cancer 42, 2374-2381. doi:10.1016/j.ejca.2006.01.061

Nwani, N. G., Condello, S., Wang, Y., Swetzig, W. M., Barber, E., Hurley, T., et al. (2019). A Novel ALDH1A1 Inhibitor Targets Cells with Stem Cell Characteristics in Ovarian Cancer. Cancers (Basel) 11, 502. doi:10.3390/ cancers 11040502

O'Callaghan, C., and Vassilopoulos, A. (2017). Sirtuins at the Crossroads of Stemness, Aging, and Cancer. Aging Cell 16, 1208-1218. doi:10.1111/acel.12685

Ogino, Y., Sato, A., Uchiumi, F., and Tanuma, S. I. (2018). Cross Resistance to Diverse Anticancer Nicotinamide Phosphoribosyltransferase Inhibitors Induced by FK866 Treatment. Oncotarget 9, 16451-16461. doi:10.18632/ oncotarget. 24731

Ogino, Y., Sato, A., Uchiumi, F., and Tanuma, S. I. (2019). Genomic and Tumor Biological Aspects of the Anticancer Nicotinamide Phosphoribosyltransferase Inhibitor FK866 in Resistant Human Colorectal Cancer Cells. Genomics 111, 1889-1895. doi:10.1016/ j.ygeno.2018.12.012

Olesen, U. H., Thougaard, A. V., Jensen, P. B., and Sehested, M. (2010). A Preclinical Study on the rescue of normal Tissue by Nicotinic Acid in HighDose Treatment with APO866, a Specific Nicotinamide Phosphoribosyltransferase Inhibitor. Mol. Cancer Ther. 9, 1609-1617. doi:10.1158/1535-7163.MCT-09-1130

Oronsky, B., Scicinski, J., Reid, T., Oronsky, A., Carter, C., Oronsky, N., et al. (2016). RRx-001, a Novel Clinical-Stage Chemosensitizer, Radiosensitizer, and Immunosensitizer, Inhibits Glucose 6-phosphate Dehydrogenase in Human Tumor Cells. Discov. Med. 21, 251-265.

Perenkov, A. D., Novikov, D. V., Sakharnov, N. A., Aliasova, A. V., Utkin, O. V., Baryshnikov, A. Iu., et al. (2012). Heterogeneous Expression of CD38 Gene in Tumor Tissue in Patients with Colorectal Cancer. Mol. Biol. (Mosk) 46, 786-791. doi:10.1134/s002689331205010x

Perez-Miller, S., Younus, H., Vanam, R., Chen, C. H., Mochly-Rosen, D., and Hurley, T. D. (2010). Alda-1 Is an Agonist and Chemical Chaperone for the Common Human Aldehyde Dehydrogenase 2 Variant. Nat. Struct. Mol. Biol. 17, 159-164. doi:10.1038/nsmb.1737

Pes, G. M., Errigo, A., Soro, S., Longo, N. P., and Dore, M. P. (2019). Glucose6-phosphate Dehydrogenase Deficiency Reduces Susceptibility to Cancer of Endodermal Origin. Acta Oncol. 58, 1205-1211. doi:10.1080/ 0284186X.2019.1616815

Petrelli, R., Felczak, K., and Cappellacci, L. (2011). NMN/NaMN Adenylyltransferase (NMNAT) and NAD Kinase (NADK) Inhibitors: Chemistry and Potential Therapeutic Applications. Curr. Med. Chem. 18, 1973-1992. doi:10.2174/092986711795590048

Pishvaian, M. J., Slack, R. S., Jiang, W., He, A. R., Hwang, J. J., Hankin, A., et al. (2018). A Phase 2 Study of the PARP Inhibitor Veliparib Plus Temozolomide in Patients with Heavily Pretreated Metastatic Colorectal Cancer. Cancer 124, 2337-2346. doi:10.1002/cncr.31309

Pishvaian, M. J., Marshall, J. L., Hwang, J. H., Malik, S. M., He, A. R., Deeken, J. F., et al. (2008). A Phase 1 Trial of GMX1777: An Inhibitor of Nicotinamide
Phosphoribosyl Transferase (NAMPRT). JCO 26, 14568. doi:10.1200/ jco.2008.26.15_suppl.14568

Plummer, R., Dua, D., Cresti, N., Drew, Y., Stephens, P., Foegh, M., et al. (2020). First-in-human Study of the PARP/tankyrase Inhibitor E7449 in Patients with Advanced Solid Tumours and Evaluation of a Novel Drug-Response Predictor. Br. J. Cancer 123, 525-533. doi:10.1038/s41416-020-0916-5

Popsavin, M., Torović, L., Svircev, M., Kojić, V., Bogdanović, G., and Popsavin, V. (2006). Synthesis and Antiproliferative Activity of Two New Tiazofurin Analogues with 2'-amido Functionalities. Bioorg. Med. Chem. Lett. 16, 2773-2776. doi:10.1016/j.bmcl.2006.02.001

Pramono, A. A., Rather, G. M., Herman, H., Lestari, K., and Bertino, J. R. (2020). NAD- and NADPH-Contributing Enzymes as Therapeutic Targets in Cancer: An Overview. Biomolecules 10, E358. doi:10.3390/biom10030358

Pusch, S., Krausert, S., Fischer, V., Balss, J., Ott, M., Schrimpf, D., et al. (2017). Panmutant IDH1 Inhibitor BAY 1436032 for Effective Treatment of IDH1 Mutant Astrocytoma In Vivo. Acta Neuropathol. 133, 629-644. doi:10.1007/s00401017-1677-y

Qi, J., Cui, C., Deng, Q., Wang, L., Chen, R., Zhai, D., et al. (2018). Downregulated SIRT6 and Upregulated NMNAT2 Are Associated with the Presence, Depth and Stage of Colorectal Cancer. Oncol. Lett. 16, 5829-5837. doi:10.3892/ ol.2018.9400

Quattrini, L., Gelardi, E. L. M., Coviello, V., Sartini, S., Ferraris, D. M., Mori, M., et al. (2020a). Imidazo[1,2-a]pyridine Derivatives as Aldehyde Dehydrogenase Inhibitors: Novel Chemotypes to Target Glioblastoma Stem Cells. J. Med. Chem. 63, 4603-4616. doi:10.1021/acs.jmedchem.9b01910

Quattrini, L., Gelardi, E. L. M., Petrarolo, G., Colombo, G., Ferraris, D. M. Picarazzi, F., et al. (2020b). Progress in the Field of Aldehyde Dehydrogenase Inhibitors: Novel Imidazo[1,2-A]pyridines against the 1A Family. ACS Med. Chem. Lett. 11, 963-970. doi:10.1021/ acsmedchemlett.9b00686

Rather, G. M., Pramono, A. A., Szekely, Z., Bertino, J. R., and Tedeschi, P. M. (2021). In Cancer, All Roads lead to NADPH. Pharmacol. Ther. 226, 107864. doi:10.1016/j.pharmthera.2021.107864

Rebollido-Rios, R., Venton, G., Sánchez-Redondo, S., Iglesias I Felip, C., Fournet, G., González, E., et al. (2020). Dual Disruption of Aldehyde Dehydrogenases 1 and 3 Promotes Functional Changes in the Glutathione Redox System and Enhances Chemosensitivity in Nonsmall Cell Lung Cancer. Oncogene 39, 2756-2771. doi:10.1038/s41388-020-1184-9

Reid, T., Dad, S., Korn, R., Oronsky, B., Knox, S., and Scicinski, J. (2014). Two Case Reports of Resensitization to Previous Chemotherapy with the Novel HypoxiaActivated Hypomethylating Anticancer Agent RRx-001 in Metastatic Colorectal Cancer Patients. Case Rep. Oncol. 7, 79-85. doi:10.1159/000358382

Reitman, Z. J., Duncan, C. G., Poteet, E., Winters, A., Yan, L. J., Gooden, D. M., et al. (2014). Cancer-associated Isocitrate Dehydrogenase 1 (IDH1) R132H Mutation and D-2-Hydroxyglutarate Stimulate Glutamine Metabolism under Hypoxia. J. Biol. Chem. 289, 23318-23328. doi:10.1074/jbc.M114.575183

Rossi, M., Jahanzaib Anwar, M., Usman, A., Keshavarzian, A., and Bishehsari, F. (2018). Colorectal Cancer and Alcohol Consumption-Populations to Molecules. Cancers (Basel) 10, 38. doi:10.3390/cancers10020038

Rubie, C., Kempf, K., Hans, J., Su, T., Tilton, B., Georg, T., et al. (2005). Housekeeping Gene Variability in normal and Cancerous Colorectal, Pancreatic, Esophageal, Gastric and Hepatic Tissues. Mol. Cel Probes 19, 101-109. doi:10.1016/j.mcp.2004.10.001

Saikolappan, S., Kumar, B., Shishodia, G., Koul, S., and Koul, H. K. (2019). Reactive Oxygen Species and Cancer: A Complex Interaction. Cancer Lett. 452, 132-143. doi:10.1016/j.canlet.2019.03.020

Samal, B., Sun, Y., Stearns, G., Xie, C., Suggs, S., and McNiece, I. (1994). Cloning and Characterization of the cDNA Encoding a Novel Human Pre-B-cell colonyenhancing Factor. Mol. Cel. Biol. 14, 1431-1437. doi:10.1128/mcb.14.2.1431

Sánchez-Aragó, M., and Cuezva, J. M. (2011). The Bioenergetic Signature of Isogenic colon Cancer Cells Predicts the Cell Death Response to Treatment with 3-bromopyruvate, Iodoacetate or 5-fluorouracil. J. Transl Med. 9, 19. doi:10.1186/1479-5876-9-19

Sánchez-Tena, S., Alcarraz-Vizán, G., Marín, S., Torres, J. L., and Cascante, M. (2013). Epicatechin Gallate Impairs colon Cancer Cell Metabolic Productivity. J. Agric. Food Chem. 61, 4310-4317. doi:10.1021/jf3052785

Singh, S., Arcaroli, J., Chen, Y., Thompson, D. C., Messersmith, W., Jimeno, A., et al. (2015). ALDH1B1 Is Crucial for Colon Tumorigenesis by Modulating 
Wnt/B-Catenin, Notch and PI3K/Akt Signaling Pathways. PLoS One 10, e0121648. doi:10.1371/journal.pone.0121648

Smeby, J., Kryeziu, K., Berg, K. C. G., Eilertsen, I. A., Eide, P. W., Johannessen, B., et al. (2020). Molecular Correlates of Sensitivity to PARP Inhibition beyond Homologous Recombination Deficiency in Pre-clinical Models of Colorectal Cancer point to Wild-type TP53 Activity. EBioMedicine 59, 102923. doi:10.1016/j.ebiom.2020.102923

Tang, M., Lu, X., Zhang, C., Du, C., Cao, L., Hou, T., et al. (2017). Downregulation of SIRT7 by 5 -fluorouracil Induces Radiosensitivity in Human Colorectal Cancer. Theranostics 7, 1346-1359. doi:10.7150/ thno. 18804

Tarrado-Castellarnau, M. (2017). Glyceraldehyde-3-phosphate Dehydrogenase Is Overexpressed in Colorectal Cancer Onset | Translational Medicine Communications | Full Text. Available at: https://transmedcomms. biomedcentral.com/articles/10.1186/s41231-017-0015-7 (Accessed July 26, 2021).

Tarrant, J. M., Dhawan, P., Singh, J., Zabka, T. S., Clarke, E., DosSantos, G., et al. (2015). Preclinical Models of Nicotinamide Phosphoribosyltransferase Inhibitor-Mediated Hematotoxicity and Mitigation by Co-treatment with Nicotinic Acid. Toxicol. Mech. Methods 25, 201-211. doi:10.3109/ 15376516.2015.1014080

Tedeschi, P. M., Bansal, N., Kerrigan, J. E., Abali, E. E., Scotto, K. W., and Bertino, J. R. (2016). NAD+ Kinase as a Therapeutic Target in Cancer. Clin. Cancer Res. 22, 5189-5195. doi:10.1158/1078-0432.CCR-16-1129

Tedeschi, P. M., Lin, H., Gounder, M., Kerrigan, J. E., Abali, E. E., Scotto, K., et al. (2015). Suppression of Cytosolic NADPH Pool by Thionicotinamide Increases Oxidative Stress and Synergizes with Chemotherapy. Mol. Pharmacol. 88, 720-727. doi:10.1124/mol.114.096727

Tempel, W., Rabeh, W. M., Bogan, K. L., Belenky, P., Wojcik, M., Seidle, H. F., et al. (2007). Nicotinamide Riboside Kinase Structures Reveal New Pathways to NAD+. Plos Biol. 5, e263. doi:10.1371/journal.pbio.0050263

Tolstikov, V., Nikolayev, A., Dong, S., Zhao, G., and Kuo, M. S. (2014). Metabolomics Analysis of Metabolic Effects of Nicotinamide Phosphoribosyltransferase (NAMPT) Inhibition on Human Cancer Cells. PLoS One 9, e114019. doi:10.1371/journal.pone.0114019

Tomita, H., Tanaka, K., Tanaka, T., and Hara, A. (2016). Aldehyde Dehydrogenase 1A1 in Stem Cells and Cancer. Oncotarget 7, 11018-11032. doi:10.18632/ oncotarget.6920

Tougeron, D., Guilloteau, K., and Karayan-Tapon, L. (2016). Absence of IDH Mutation in Colorectal Cancers with Microsatellite Instability. Dig. Liver Dis. 48, 681-683. doi:10.1016/j.dld.2016.02.019

Travelli, C., Aprile, S., Mattoteia, D., Colombo, G., Clemente, N., Scanziani, E., et al. (2019a). Identification of Potent Triazolylpyridine Nicotinamide Phosphoribosyltransferase (NAMPT) Inhibitors Bearing a 1,2,3-triazole Tail Group. Eur. J. Med. Chem. 181, 111576. doi:10.1016/ j.ejmech.2019.111576

Travelli, C., Consonni, F. M., Sangaletti, S., Storto, M., Morlacchi, S., Grolla, A. A., et al. (2019b). Nicotinamide Phosphoribosyltransferase Acts as a Metabolic Gate for Mobilization of Myeloid-Derived Suppressor Cells. Cancer Res. 79, 1938-1951. doi:10.1158/00085472.CAN-18-1544

van de Donk, N. W. C. J., Richardson, P. G., and Malavasi, F. (2018). CD38 Antibodies in Multiple Myeloma: Back to the Future. Blood 131, 13-29. doi:10.1182/blood-2017-06-740944

van der Waals, L. M., Borel Rinkes, I. H. M., and Kranenburg, O. (2018). ALDH1A1 Expression Is Associated with Poor Differentiation, 'rightSidedness' and Poor Survival in Human Colorectal Cancer. PLoS One 13, e0205536. doi:10.1371/journal.pone.0205536

Vander Heiden, M. G., Cantley, L. C., and Thompson, C. B. (2009). Understanding the Warburg Effect: The Metabolic Requirements of Cell Proliferation. Science 324, 1029-1033. doi:10.1126/science.1160809

Vassalli, G. (2019). Aldehyde Dehydrogenases: Not Just Markers, but Functional Regulators of Stem Cells. Stem Cell Int 2019, 3904645. doi:10.1155/2019/ 3904645

Vassilopoulos, A., Fritz, K. S., Petersen, D. R., and Gius, D. (2011). The Human Sirtuin Family: Evolutionary Divergences and Functions. Hum. Genomics 5, 485-496. doi:10.1186/1479-7364-5-5-485
Wang, B., Ye, Y., Yang, X., Liu, B., Wang, Z., Chen, S., et al. (2020). SIRT2dependent IDH1 Deacetylation Inhibits Colorectal Cancer and Liver Metastases. EMBO Rep. 21, e48183. doi:10.15252/embr.201948183

Wang, C., Jette, N., Moussienko, D., Bebb, D. G., and Lees-Miller, S. P. (2017a). ATM-deficient Colorectal Cancer Cells Are Sensitive to the PARP Inhibitor Olaparib. Transl Oncol. 10, 190-196. doi:10.1016/ j.tranon.2017.01.007

Wang, C., Jette, N., Moussienko, D., Bebb, D. G., and Lees-Miller, S. P. (2017b). ATM-deficient Colorectal Cancer Cells Are Sensitive to the PARP Inhibitor Olaparib. Transl Oncol. 10, 190-196. doi:10.1016/ j.tranon.2017.01.007

Wang, Y., Sun, X., Ji, K., Du, L., Xu, C., He, N., et al. (2018a). Sirt3-mediated Mitochondrial Fission Regulates the Colorectal Cancer Stress Response by Modulating the Akt/PTEN Signalling Pathway. Biomed. Pharmacother. 105, 1172-1182. doi:10.1016/j.biopha.2018.06.071

Wang, Y., Yang, H., Shen, C. J., Ge, J. N., and Lin, J. (2018b). Association between Alcohol Consumption and Colorectal Cancer Risk: a Case-Control Study in the Han Chinese Population. Eur. J. Cancer Prev. 27, 433-437. doi:10.1097/ CEJ.0000000000000355

Watson, M., Roulston, A., Bélec, L., Billot, X., Marcellus, R., Bédard, D., et al. (2009). The Small Molecule GMX1778 Is a Potent Inhibitor of NAD+ Biosynthesis: Strategy for Enhanced Therapy in Nicotinic Acid Phosphoribosyltransferase 1-deficient Tumors. Mol. Cel Biol 29, 5872-5888. doi:10.1128/MCB.00112-09

Whitehall, V. L., Dumenil, T. D., McKeone, D. M., Bond, C. E., Bettington, M. L., Buttenshaw, R. L., et al. (2014). Isocitrate Dehydrogenase 1 R132C Mutation Occurs Exclusively in Microsatellite Stable Colorectal Cancers with the CpG Island Methylator Phenotype. Epigenetics 9, 1454-1460. doi:10.4161/ 15592294.2014.971624

Wilsbacher, J. L., Cheng, M., Cheng, D., Trammell, S. A. J., Shi, Y., Guo, J., et al. (2017). Discovery and Characterization of Novel Nonsubstrate and Substrate NAMPT Inhibitors. Mol. Cancer Ther. 16, 1236-1245. doi:10.1158/15357163.MCT-16-0819

Yan, X., Zhao, J., and Zhang, R. (2017). Visfatin Mediates Doxorubicin Resistance in Human Colorectal Cancer Cells via up Regulation of Multidrug Resistance 1 (MDR1). Cancer Chemother. Pharmacol. 80, 395-403. doi:10.1007/s00280-0173365-y

Yang, S. M., Yasgar, A., Miller, B., Lal-Nag, M., Brimacombe, K., Hu, X., et al. (2015). Discovery of NCT-501, a Potent and Selective Theophylline-Based Inhibitor of Aldehyde Dehydrogenase 1A1 (ALDH1A1). J. Med. Chem. 58, 5967-5978. doi:10.1021/acs.jmedchem.5b00577

Yang, W., Wang, Y., Wang, W., Chen, Z., and Bai, G. (2018). Expression of Aldehyde Dehydrogenase 1A1 (ALDH1A1) as a Prognostic Biomarker in Colorectal Cancer Using Immunohistochemistry. Med. Sci. Monit. 24, 2864-2872. doi:10.12659/MSM.910109

Yau, E. H., Kummetha, I. R., Lichinchi, G., Tang, R., Zhang, Y., and Rana, T. M. (2017). Genome-Wide CRISPR Screen for Essential Cell Growth Mediators in Mutant KRAS Colorectal Cancers. Cancer Res. 77, 6330-6339. doi:10.1158/ 0008-5472.CAN-17-2043

Ye, C., Qi, L., Li, X., Wang, J., Yu, J., Zhou, B., et al. (2020). Targeting the NAD+ Salvage Pathway Suppresses APC Mutation-Driven Colorectal Cancer Growth and Wnt/ $\beta$-Catenin Signaling via Increasing Axin Level. Cell Commun Signal 18, 16. doi:10.1186/s12964-020-0513-5

Yoon, M. J., Yoshida, M., Johnson, S., Takikawa, A., Usui, I., Tobe, K., et al. (2015). SIRT1-Mediated eNAMPT Secretion from Adipose Tissue Regulates Hypothalamic NAD+ and Function in Mice. Cell Metab 21, 706-717. doi:10.1016/j.cmet.2015.04.002

Yu, M., Chen, S., Hong, W., Gu, Y., Huang, B., Lin, Y., et al. (2019). Prognostic Role of Glycolysis for Cancer Outcome: Evidence from 86 Studies. J. Cancer Res. Clin. Oncol. 145, 967-999. doi:10.1007/s00432-019-02847-w

Yun, J., Mullarky, E., Lu, C., Bosch, K. N., Kavalier, A., Rivera, K., et al. (2015). Vitamin C Selectively Kills KRAS and BRAF Mutant Colorectal Cancer Cells by Targeting GAPDH. Science 350, 1391-1396. doi:10.1126/ science.aaa5004

Zhang, H., and Fu, L. (2021). The Role of ALDH2 in Tumorigenesis and Tumor Progression: Targeting ALDH2 as a Potential Cancer Treatment. Acta Pharm. Sin B 11, 1400-1411. doi:10.1016/j.apsb.2021.02.008 
Zhang, X., Zhang, X., Li, Y., Shao, Y., Xiao, J., Zhu, G., et al. (2017). PAK4 Regulates G6PD Activity by P53 Degradation Involving colon Cancer Cell Growth. Cel Death Dis 8, e2820. doi:10.1038/cddis.2017.85

Zhang, Y., Nie, L., Xu, K., Fu, Y., Zhong, J., Gu, K., et al. (2019). SIRT6, a Novel Direct Transcriptional Target of FoxO3a, Mediates colon Cancer Therapy. Theranostics 9, 2380-2394. doi:10.7150/thno.29724

Zhang, Y. J., Wang, Z., Sprous, D., and Nabioullin, R. (2006). In Silico design and Synthesis of Piperazine-1-Pyrrolidine-2,5-Dione Scaffold-Based Novel Malic Enzyme Inhibitors. Bioorg. Med. Chem. Lett. 16, 525-528. doi:10.1016/j.bmcl.2005.10.065

Zhou, P., Li, X. P., Jiang, R., Chen, Y., Lv, X. T., Guo, X. X., et al. (2019). Evodiamine Inhibits Migration and Invasion by Sirtl-Mediated post-translational Modulations in Colorectal Cancer. Anticancer Drugs 30, 611-617. doi:10.1097/CAD.0000000000000760

Zu, G., Ji, A., Zhou, T., and Che, N. (2016). Clinicopathological Significance of SIRT1 Expression in Colorectal Cancer: A Systematic Review and Meta Analysis. Int. J. Surg. 26, 32-37. doi:10.1016/j.ijsu.2016.01.002
Conflict of Interest: The authors declare that the research was conducted in the absence of any commercial or financial relationships that could be construed as a potential conflict of interest.

Publisher's Note: All claims expressed in this article are solely those of the authors and do not necessarily represent those of their affiliated organizations, or those of the publisher, the editors and the reviewers. Any product that may be evaluated in this article, or claim that may be made by its manufacturer, is not guaranteed or endorsed by the publisher.

Copyright (C) 2021 Colombo, Gelardi, Balestrero, Moro, Travelli and Genazzani. This is an open-access article distributed under the terms of the Creative Commons Attribution License (CC BY). The use, distribution or reproduction in other forums is permitted, provided the original author(s) and the copyright owner(s) are credited and that the original publication in this journal is cited, in accordance with accepted academic practice. No use, distribution or reproduction is permitted which does not comply with these terms. 